\title{
Cause or consequence? Exploring the role of phenotypic plasticity and genetic polymorphism in the emergence of phenotypic spatial patterns of the European eel
}

\begin{tabular}{|r|l|}
\hline Journal: & Canadian Journal of Fisheries and Aquatic Sciences \\
\hline Manuscript ID & cjfas-2016-0214.R1 \\
\hline Manuscript Type: & Article \\
\hline Date Submitted by the Author: & $29-$ Oct-2016 \\
\hline Complete List of Authors: & $\begin{array}{l}\text { Mateo, Maria; Irstea Centre de Bordeaux, } \\
\text { Lambert, Patrick; IRSTEA, Estuarine Ecosystems and Diadromous Fish } \\
\text { Tétard, Stéphane; EDF Recherche et Developpement } \\
\text { Castonguay, Martin; Ministère des Pêches et des Océans, } \\
\text { Ernande, Bruno; Laboratoire Ressources Halieutiques } \\
\text { Drouineau, Hilaire; Cemagref, }\end{array}$ \\
\hline Keyword: & $\begin{array}{l}\text { Anguilla anguilla, phenotypic plasticity, genetic polymorphism, life history } \\
\text { theory, modeling }\end{array}$ \\
\hline &
\end{tabular}

\section{SCHOLARONE"}

Manuscripts 
1 Cause or consequence? Exploring the role of phenotypic plasticity and genetic polymorphism in the

2 emergence of phenotypic spatial patterns of the European eel

3

4 Authors:

- Maria MATEO (corresponding author)

- Affiliations: Irstea, UR EABX Ecosystèmes aquatiques et changements globaux, HYNES Irstea - EDF R\&D

- Address: 50 avenue du Verdun, 33612 Cestas, France

○ Tel: +33(0)5 57890998

○ Email: maria.mateo@irstea.fr

- Patrick LAMBERT

- Affiliations: Irstea, UR EABX Ecosystèmes aquatiques et changements globaux, HYNES Irstea - EDF R\&D

- Address: 50 avenue du Verdun, 33612 Cestas, France

○ Email: patrick.lambert@irstea.fr

- Affiliations: EDF R\&D, HYNES Irstea - EDF R\&D, Laboratoire National d'Hydraulique et Environnement

○ Email: stephane.tetard@edf.fr

- Affiliations: IFREMER, Laboratoire Ressources Halieutiques de Boulogne 
- Hilaire DROUINEAU

- Affiliations: Irstea, UR EABX Ecosystèmes aquatiques et changements globaux, HYNES

Irstea - EDF R\&D 


\section{$34 \quad 1$ Abstract}

The European eel (Anguilla anguilla), and generally, temperate eels, are relevant species for

36 studying adaptive mechanisms to environmental variability because of their large distribution areas

37 and their limited capacity of local adaptation. In this context, GenEveel, an individual-based

38 optimization model, was developed to explore the role of adaptive phenotypic plasticity and genetic-

39 dependent habitat selection, in the emergence of observed spatial life-history traits patterns for eels.

40 Results suggest that an interaction of genetically and environmentally controlled growth may be the

41 basis for genotype-dependent habitat selection, whereas plasticity plays a role in changes in life-

42 history traits and demographic attributes. Therefore, this suggests that those mechanisms are

43 responses to address environmental heterogeneity. Moreover, this brings new elements to explain

44 the different life strategies of males and females. A sensitivity analysis showed that the parameters

45 associated with the optimization of fitness and growth genotype were crucial in reproducing the

46 spatial life-history patterns. Finally, it raises the question of the impact of anthropogenic pressures

47 that can cause direct mortalities but also modify demographic traits, and act as a selection pressure.

48

Keywords: phenotypic plasticity, Anguilla anguilla, genetic polymorphism, life history theory,

50 modeling 


\section{Introduction}

Life-history theory posits that the schedule and duration of life-history traits are the result of

53 natural selection to optimize individual fitness (Clark 1993; Giske et al. 1998). Optimal solutions

54 greatly depend on environmental conditions, and consequently, living organisms have developed

55 different adaptive mechanisms to address environmental variability. Among them, local adaptation

56 theory posits that natural selection favors the most well adapted genotypes in each type of

57 environment. In a context of limited genetic exchange between environments, this may lead to

58 isolation and speciation (Williams 1996; Kawecki and Ebert 2004). Phenotypic plasticity might also be

59 an adaptive response to an heterogeneous environment (Levins 1963; Gotthard and Nylin 1995;

60 Pigliucci 2005). Phenotypic plasticity refers to the possibility of a genotype to produce different

61 phenotypes depending on environmental conditions. In some cases, increases in fitness occur

62 because of plastic phenotypes compared to non-plastic ones, and that consequently, phenotypic

63 plasticity may be selected by natural selection (Schlichting 1986; Sultan 1987; Travis 1994).

64 Adaptation to environment heterogeneity is a key issue for temperate anguilids, Anguilla

65 anguilla, A. japonica, A. rostrata, three catadromous species that display remarkable similarities in

66 their life-history traits (Daverat et al. 2006; Edeline 2007). The European eel (A. anguilla) is widely

67 distributed from Norway to Morocco, grows in contrasting environments, and displays considerable

68 phenotypic variation. The species displays a complex life cycle: reproduction takes place in the

69 Sargasso Sea, larvae (or leptocephali) are transported by ocean currents to European and North

70 African waters, where they experience their first metamorphosis to become glass eels. These

71 juveniles colonize continental waters and undergo progressive pigmentation changes to become

72 yellow eels. The growth phase lasts between 2 and 20 years depending upon the region and sex of

73 the eels (Vollestad 1992). At the end of this stage, yellow eels metamorphose again into silver eels,

74 which mature during the migration to their spawning area in the Sargasso Sea. The population is

75 panmictic, resulting in a homogeneous population, from a genetic viewpoint (Palm et al. 2009; Als et 
76 al. 2011; Côté et al. 2013). This panmixia combined with a long and passive larval drift limit the 77 possibility of adaptation to local environments. However, spatial patterns of different life traits, 78 including growth rate (Daverat et al. 2012; Geffroy and Bardonnet 2012), sex (Helfman et al. 1987; 79 Tesch 2003; Davey and Jellyman 2005), length at maturity (Vollestad 1992; Oliveira 1999), and habitat 80 use (De Leo and Gatto 1995; Daverat et al. 2006; Edeline 2007) are observed and correlated with environmental patterns.

82 Growth rates greatly vary depending on latitude, temperature, sex (Helfman et al. 1987) but 83 also on habitat characteristics (Cairns et al. 2009). Indeed, eel can settle in a wide range of habitats 84 (De Leo and Gatto 1995; Daverat et al. 2006; Geffroy and Bardonnet 2012) and faster growth is observed in brackish waters than in freshwater (Daverat et al. 2012). Slower growth in freshwater habitats is sometimes assumed to be compensated for by lower mortalities and Edeline (2007)

87 suggested that habitat choice could be the result of a conditional evolutionary stable strategy. However, Cairns et al. (2009) questioned this assumption because they did not observe strong variation in mortality rates between habitats. Spatial patterns were also observed with respect to sex ratios, with female biased sex ratios in the upper part of river catchments (Tesch 2003) and in the 91 northern part of the distribution range (Helfman et al. 1987; Davey and Jellyman 2005). However, sex 92 is not determined at birth but is determined by environmental factors (Oliveira 2001; Davey and 93 Jellyman 2005; Geffroy and Bardonnet 2012). Population density also plays a role in this mechanism: 94 males are favored at high densities, whereas low densities favor females (Tesch 2003). This is 95 important because males and females have different life-history strategies (Helfman et al. 1987). The 96 reproductive success of a male does not vary with body size, and consequently, males are assumed

97 to follow a time-minimizing strategy, leaving continental waters as soon as they have enough energy 98 to migrate to the spawning grounds (Vollestad 1992). However, a female's reproductive success is 99 constrained by a trade-off between fecundity, which increases with length, and survival, which 100 decreases with length. Consequently, females are assumed to adopt a size-maximizing strategy 
101 (Helfman et al. 1987). Strong differences in female length at silvering were observed among habitats 102 and latitudes (Oliveira 1999).

103 Because local adaptation is impossible, this raises two questions: (i) are those life-history 104 trait patterns resulting from an adaptive response to environmental heterogeneity, and (ii) which 105 adaptation mechanisms have been selected. Despite panmixia, previous researchers (Gagnaire et al. 106 2012; Ulrik et al. 2014; Pavey et al. 2015) have detected genetic differences correlated with 107 environmental gradients and assumed that those differences were reshuffled at each generation 108 because of panmixia. Common garden experiments have been used to test the respective 109 contributions of genetic and plastic mechanisms on phenotypic differences observed in glass eels 110 found in distinct locations. The results revealed genetic patterns related to geographic zones in 111 American eels, whereas individual growth rates had a genetic basis and could be sex-dependent 112 (Côté et al. 2009, 2014, 2015). Building on this, Boivin et al. (2015) studied the influence of salinity 113 preferences and geographic origin on habitat selection and growth in American eels, demonstrating 114 genetic-based differences for growth between glass eels from different origins. However, these 115 experiments also confirmed the contribution of phenotypic plasticity that allowed individuals to 116 develop quick and effective responses to environmental variability (Hutchings et al. 2007). Several 117 traits have been proposed as plastic: growth habitats (Daverat et al. 2006; Edeline 2007), growth 118 rates (Geffroy and Bardonnet 2012), and length at silvering (Vollestad 1992). Understanding the 119 adaptive mechanisms that explain this diversity is crucial to environmental conservation and 120 management (Brodersen and Seehausen 2014).

121 As a result of a decline observed since the 1980s, the European eel is now listed as critically 122 endangered in the IUCN Red List (Jacoby and Gollock 2014) and the European Commission enforced a 123 European Regulation, which requires a reduction in all sources of anthropogenic mortality (obstacles, 124 loss of habitat, fisheries, pollution, and global change) (Council of the European Union 2007). 125 However, those anthropogenic pressures are not uniformly distributed (Dekker 2003) and acts on 126 specific fractions of the stock isolated in river catchments (Dekker 2000), with heterogeneous life- 
127 history traits because of the spatial phenotypic variability. This strong spatial heterogeneity of 128 anthropogenic pressures affecting the eel population in Europe combined with this spatial 129 phenotypic variability at both the distribution area and river catchment scales causes specific 130 challenges for management, because it impairs our ability to assess the effect of anthropogenic 131 pressures on the whole stock and to coordinate management actions (Dekker 2003, 2009). Recently, a model called EvEel (evolutionary ecology-based model for eel) was developed to explore the contribution of adaptive phenotypic plasticity in the emergence of observed phenotypic patterns: sex ratio, length at silvering, and habitat use (Drouineau et al. 2014). Assuming fitness maximization, the model was able to mimic most observed patterns at both river catchment and distribution area scales. The result confirmed the probable role of adaptive phenotypic plasticity in

137 response to environmental variability. However, recent findings demonstrated the existence of 138 genetic differences in growth traits in a wide range of different habitats (Côté et al. 2009, 2014, 2015; 139 Boivin et al. 2015). Building on these new results, we developed GenEveel, a new version of EvEel, 140 which introduces a bimodal growth distribution (fast and slow growers) for individuals, as observed 141 by Côté et al. (2015), and considers phenotypic plasticity in life-history traits and demographic 142 attributes as in EvEel. Because individuals have different intrinsic growth and mortality rates, they 143 can be favored differently among environments, opening the door to conditional habitat selection. In 144 this study, we used GenEveel to test whether simultaneously considering genetically distinct 145 individuals and phenotypic plasticity improves model performance. Pattern orienting modelling was 146 used to detect the reproduced spatial patterns of EvEel and other patterns based on the distribution 147 of the different individual's types. 


\section{Materials and methods}

$150 \quad 3.1$ Model description

151 The model description follows the Overview, Design concepts, and Details (ODD) protocol

152 (Grimm et al. 2006, 2010):

\section{3.1.1Overview}

\subsubsection{Purpose}

GenEveel is a model based on a former model called EvEel (Drouineau et al. 2014), but

includes a genetic component. It is an individual-based population model that predicts emergent life-

157

history spatial patterns depending on adaptive mechanisms and environmental heterogeneity.

Emergent patterns can later be compared to observed spatial patterns in freshwater life stages of

European eels in order to (i) confirm that observed phenotypic patterns can plausibly result from adaptive responses to environmental heterogeneity, (ii) validate that phenotypic plasticity for length at silvering, sex determination, habitat choice, and genetic polymorphism (slow growers and fast growers) with conditional habitat selection can explain those patterns.

\subsubsection{State variables and scales}

Temporal scales: the model simulates a population generation. It has no sensu stricto time until maturation.

Entities and spatial scales: a Von Bertalanffy growth function is assumed for individual growth. Each individual $i$ is characterized by an intrinsic Brody growth coefficient $K_{i}$ and a natural mortality rate $M_{i}$. Based on Côté et al. (2015), who observed two clusters in growth rates, we build a

170 simple quantitative-genetic model assuming that growth is coded for by a single gene with two

171 variations. Therefore, we assumed that there are two types of individuals called (i) fast-growing 
172 individuals for which $K i=K f a s t$ and $M i=M f a s t$ and (ii) slow-growing individuals for which $K i=K s l o w$ 173 and $\mathrm{Mi}=$ Mslow. At the end of the simulation, individuals are characterized by a sex, length at 174 silvering, corresponding fecundity (if female), position in the river catchment, and survival rate until 175 silvering.

176 The river catchment environment was represented by a sequence of cells of the same size.

177 The first cell represents the river mouth, whereas the $n$th cell represents the source of the river. 178 Because it was observed that an individual grows faster downstream than upstream (Acou et al. 179 2003; Melià et al. 2006), we assumed that realized growth rate in a cell depends on both intrinsic

\subsubsection{Process overview and scheduling}

The model has two main steps. In a first step, individuals select their growth habitat (a cell in the catchment) and determine a sex (male or female) one after another (random order). To do that, fitness is calculated for each combination of sex and cell (a quasi-Newton algorithm is used to estimate the lengths at silvering that optimize female fitness in each cell). Individuals are assumed to select the combination with highest fitness given the choices made by former individuals. Once this step is finished (i.e., all individuals have a growth habitat and sex), using the quasi-Newton algorithm we estimated the optimal length at silvering for all females (males have a constant length at silvering) given the positions of fishes from step 1 , and then compute corresponding survival rates until computer algorithm (Figure 2):

194 (1) For each individual i:

$195-\quad$ For each cell $x$ :

196 C Compute $\pi_{m}(x)$ given positions of individuals $\{1, \ldots, i-1\}$ 
(2) For each individual i:

$200-$ For each cell $x$ :

$201 \quad \cdot \quad$ if $\operatorname{sex}(\mathrm{i})=$ male

$202 \quad L_{s}(i)=L_{s m}$

$203 \cdot$ else

$204 L_{s}(i)=\arg _{L} \max \left(\pi_{f}\left(x, L_{s f}\right)\right)$ given positions of individuals $\{1, \ldots, n\}$

205 where fitness is defined in equations 9 and 10 for females and males respectively.

\section{3.1.2 Design concept}

207

208

209

210

211

212

213

214

215

216

217

218

\subsubsection{Basic principles}

Consistent with life-history theory and optimal foraging theory, the model uses an optimization approach in which individuals "respond to choices" so as to select and fix the adaptive traits, maximizing their expected fitness given their environment (Parker and Maynard Smith 1990; McNamara and Houston 1992; Giske et al. 1998; Railsback and Harvey 2013).

\subsubsection{Emergence}

Using the pattern-oriented modelling approach (Grimm and Railsback 2012), GenEveel compares predicted spatial patterns with those observed in real river catchments. Five emergent population spatial patterns were analyzed from the literature:

(i) higher density downstream than upstream

(ii) higher length at silvering upstream than downstream

(iii) male-biased sex ratio downstream and female-biased sex ratio upstream 
219 (iv) more individuals characterized with the fast-growing genotype downstream than upstream,

220 which was mainly characterized by the slow-growing genotype

221 (v) the phenotypic response led to faster growth rate downstream than upstream.

\section{$222 \quad 3.1 .2 .3$ Adaptation}

Individuals have three adaptive traits: sex-determination, length at silvering for females, and

224 choice of growth habitat (cell in the grid). These traits are assumed to maximize the predicted 225 objective function (i.e., the individual fitness).

\subsubsection{Predictions}

We assumed that individuals could perfectly predict expected fitness given previous choices and could make the most appropriate choices.

\subsubsection{Sensing}

In the model, individuals are able to "sense" fitness, which was a function of a density(Bevacqua et al. 2011; Daverat et al. 2012).

\subsubsection{Interaction}

Interactions occurred through growth habitat selection, sex determination, and densitydependent mortality.

\subsubsection{Stochasticity} growing genotype $(\operatorname{Pr}=0.5)$ or by a fast-growing genotype $(\operatorname{Pr}=0.5)$. Then stochasticity occurred in the order of individuals for step 1. 


\section{$241 \quad$ 3.1.2.8 Observations}

242 Five spatial patterns were computed at the end of the simulation:

243 (i) number of individuals per cell

244 (ii) mean length at silvering per cell

245 (iii) sex ratio (proportion of females) per cell

246 (iv) ratio of fast-growing genotype per cell

247 (v) phenotypic response of mean realized growth rate per cell.

248 These five patterns corresponded to five patterns available in the literature. Simulated patterns (i),

249 (iv), (v) was said to be consistent with the literature when a negative trend from downstream to 250 upstream was observed, whereas patterns (ii), (iii) were said to be consistent with the literature 251 when a positive trend was observed from downstream to upstream.

\section{3.1.3 Details}

\section{$253 \quad$ 3.1.3.1 Initialization}

254 At the beginning of the simulation, the catchment was empty. $N$ individuals were created and 255 attributed to the slow-growing or fast-growing genotype with probability 0.5 and had a length 7.5 $256 \mathrm{~cm}$. They had not yet entered the river catchment.

\section{$257 \quad$ 3.1.3.2 Input data}

We tested the model using a reference simulation. Values of parameters were obtained from

259 the literature (Table 1). The outputs of the model were identified based on spatial patterns as 260 previously defined in Observations. 
261

262

263

264

265

266

267

268

269

270

271

272

273

274

275

276

277

278

279

280

281

282

283

\subsubsection{Submodels}

Most of the submodels were similar to submodels from EvEel. Consequently, we provide here only the novelties and the equations that are required for a better understanding of the model. Further details are provided in (Drouineau et al. 2014).

- Growth and silvering

Growth rate was assumed the outcome of an intrinsic Brody growth coefficient $(K i)$, which is modulated by an environmental effect. This combination resulted in a phenotypic growth rate. Within the river, growth rates were significantly faster downstream than upstream (even for the same individual). Therefore, we assumed that individual $i$ would have a growth rate $K(i, x)$ in cell $x$ given by:

(1) $K(\mathrm{i}, \mathrm{x})=r_{K} \cdot K(\mathrm{i}, \mathrm{n})+\left(K(\mathrm{i}, 1)-r_{K} \cdot K(\mathrm{i}, \mathrm{n})\right) \cdot$ cauchit $\left(\frac{x}{n}, \gamma_{K}\right)$

(2) cauchit $(x, \gamma)=1-\frac{2}{\pi} \cdot \operatorname{atan}\left(\frac{x^{2}}{\gamma}\right)$

where $r_{k}$ defined the ratio between upstream and downstream growth rate, $K(i, 1)$ is the growth rate in cell $1, n$ is the total cells in the river catchment and cauchit was a mathematical function similar to the sigmoid function, but which allowed asymmetrical patterns (by modifying the parameter $\gamma$ ) to model, for example, a small brackish area in the downstream part of the catchment and a large freshwater zone upstream.

Individual's growth was simulated by a Von Bertalanffy function:

(3) $L(t, i, x)=L_{\infty}\left[1-e^{-K(i, x)\left(t-t_{0}\right)}\right]$

where $L(t, i, x)$ was the length at time $t$ and $L_{\infty}$ and $K(i, x)$, the Von Bertalanffy parameters in cell $x$ for individual $i$.

From this equation, we could calculate the time required to reach the length at silvering.

(4) As $(i, x)=\frac{1}{K(i, x)} \cdot \log \left(\frac{L_{\infty}-L g}{L_{\infty}-\operatorname{Ls}(i, x)}\right)$ 
284 where $L g$ was the length at recruitment and $L s(i, x)$ was the length at silvering, which was constant

285 for males, and a fitness maximizing variable for females.

286

- Survival

287

Mortality rate was assumed the result of three factors: density-dependence, intrinsic, and $\mathrm{Mi}$ modulated by an environmental effect. Because natural mortality was sometimes assumed to be smaller upstream than downstream (Moriarty 2003; Daverat and Tomás 2006), we assumed that the instantaneous natural mortality without density-dependence in cell $x$ for individual $i, M(i, x)$ was:

291

(5) $M(\mathrm{i}, \mathrm{x})=r_{M} \cdot M(\mathrm{i}, \mathrm{n})+\left(M(\mathrm{i}, 1)-r_{M} \cdot M(\mathrm{i}, \mathrm{n})\right) \cdot$ cauchit $\left(\frac{x}{n}, \gamma_{M}\right)$

where $r_{m}$ is the ratio between upstream and downstream instantaneous mortality rate and $\mathrm{M}(\mathrm{i}, 1)$ was the natural mortality in cell 1.

294 To account for the additional density-dependent mortality, we assumed that natural mortality increased linearly with density with an intensity $\alpha$ as in EvEel:

(6) $M_{d}(\mathrm{i}, \mathrm{x})=M(\mathrm{i}, \mathrm{x})+N(\mathrm{i}, \mathrm{x}) \cdot \alpha$

where $N$ was the number of competitors in cell $x$. An eel was assumed a competitor if it had an intrinsic growth rate greater or equal to $K i$. This corresponded to an asymmetric growth rate with larger individuals harassing smaller individuals. The basis of this assumption was the intraspecific competition, which leads to compete for limited resources between individuals of different sizes

301 (Francis 1983; Juanes et al. 2002).

302 Given equation (4) and this survival rate, we could calculate the probability of surviving until silvering 303 as:

304

(7) $p(i, x)=\mathrm{e}^{-M_{d}(i, x) \cdot \operatorname{As}(i, x)}=\left(\frac{L_{\infty}-L g}{L_{\infty}-\operatorname{Ls}(i, x)}\right)^{\frac{-M_{d}(i, x)}{K(i, x)}}$ In any optimization model, an important component is the computation of the fitness. 
specific fitness functions. Males were known to adopt a time minimizing strategy (Helfman et al.

309 1987), with constant length at silvering. Therefore, male fitness was proportional to survival rate

310 until length at silvering. However, females follow a size-maximizing strategy in which length at

311 silvering was constrained by a trade-off between survival and fecundity (Helfman et al. 1987).

312 Consequently, we assumed that female fitness was the product of fecundity at an optimal length at

313 silvering (based on an allometric relationship, fecundity is assumed to be a power function of length)

314 multiplied by the probability of survival until this length at silvering. In the model, individuals were

315 assumed to determine their sex according to the relative potential male and female fitness. To make

316 fitness values comparable, we rescaled male fitness (which was the probability of survival) into an

317 expectation of egg production (the scale of female fitness). To do that, we multiplied the male

318 survival by a constant that would be similar to fertility. Hence, we had to specify a value for fertility

319 with an order of magnitude similar to fecundity. The first solution might be to fix the fertility value

320 equal to the fecundity of silver females having a length equal to male length at silvering. However,

321 with this solution, female fitness will always be greater (because females can optimize their length at

322 silvering). Consequently, fertility has to be slightly greater such that male fitness can be sometimes

323 be greater than female fitness (but not too much, to avoid male fitness always being superior). These

324 resulted in the following equations:

325 (8) fecundity $\left(L_{s_{f}}(i, x)\right)=\left(a_{1}+a \cdot L_{s_{f}}(i, x)^{b}\right)$

326 where $a 1, a$ and $b$ are the parameters of the allometric relationship linking fecundity and female

327 length at silvering $L_{s f}(i, x)$ (Andrello et al. 2011; Melia et al. 2006).

328

(9) $\pi_{f}(i, x)=$ fecundity $\left(L_{s_{f}}(i, x)\right) \cdot\left[\frac{L_{\infty}-L_{g}}{L_{\infty}-L_{s_{f}}(i, x)}\right]^{\frac{-M_{f}(i, x)}{K(i, x)}}$

329

(10) $\pi_{m}(i, x)=$ fertility $\cdot\left[\frac{L_{\infty}-L_{g}}{L_{\infty}-L_{s_{m}}(i, x)}\right]^{\frac{-M_{m}(i, x)}{K(i, x)}}$ 


\subsection{Model exploration}

\section{$331 \quad 3.2 .1$ Reference simulation}

332

The reference simulation consisted of a simulation using parameter values in Table 1, i.e. the best set of values found in the literature. After simulating this scenario, we analyzed the different patterns. Mann-Kendall tests were implemented on each pattern to detect a monotonic upward or downward trend of the variable of interest confirming the spatial patterns previously defined. The correlation coefficient of this non-parametric test was denoted by $\tau$.

\subsubsection{Experimental design}

Simulation design is a classical tool to explore complex models. Typically, the goal is to assess the sensitivity of results to uncertain model parameters. We developed such an experimental design to (i) assess the influence of uncertain parameters on the simulated patterns (Table 1 ) and (ii) derive environmental and population dynamics for all the patterns that were correctly modelled.

Seventeen uncertain parameters were identified in the model (Table 1) and they were dispatched into twelve groups: number of glass eel entering the catchment freshwater $(N)$, parameters that impact the male fitness (fertility and male length at silvering, $\left.L_{s m}\right)$, fast growing genotype $\left(K_{\text {fast }}(i, 1)\right.$ and $\left.M_{\text {fast }}(i, 1)\right)$, slow-growing genotype $\left(K_{\text {slow }}(i, 1)\right.$ and $\left.M_{\text {slow }}(i, 1)\right)$, proportion of individuals that grow slowly (propK), intensity of density-dependence $(\alpha)$, cells of river catchment $(n)$, regression coefficient from fecundity at length $(b)$, asymptotic length $\left(L_{\infty}\right)$, length at recruitment $\left(L_{g}\right)$, ratio between upstream and downstream instantaneous growth and mortality rates $\left(r_{k}\right.$ and $\left.r_{m}\right)$, and the shape parameter of growth and mortality $\left(\gamma_{k}\right.$ and $\left.\gamma_{m}\right)$. Groups were composed of parameters that have are assumed to influence the model in similar directions, a method called group-screening (Kleijnen 1987). A low and high value was set for each parameter around the reference value, with 20\% variation (Drouineau et al. 2006; Rougier et al. 2015), except for three sets of parameters: fertility and $L_{s m}$ (as a minimum value, fertility corresponded to the fecundity of a female with a length 
354 at silvering equals to male length at silvering; otherwise, female fitness would always be superior to 355 male fitness), and growth genotypes (to avoid overlap between them), where the range of variation 356 was less. We then conducted a fractional factorial design of resolution $V\left(2^{12-4}=256\right.$ combinations $)$.

357 This kind of orthogonal designs allows to explore main effects and first order interactions without 358 confusion. To account for model stochasticity, we conducted 10 replicates for each of the 256 359 combinations leading to 2560 simulations. The five patterns were calculated for each simulation 360 producing an output table with 2560 lines (one per simulation) and five columns containing the tau 361 value of the Mann-Kendall trend tests for each pattern (a negative tau value indicates a negative 362 trend from downstream to upstream while a positive tau indicates a positive trend from downstream to upstream).

\section{Results}

\subsection{Reference simulation}

In the reference simulation, GenEveel mimicked the five spatial patterns at the catchment scale (Fig. 3) Males were concentrated in the downstream section of the river where density was higher (Helfman et al. 1987; Tesch 2003; Davey and Jellyman 2005). Fast growers preferentially settled in downstream habitats, whereas slow growers tended to move upstream to avoid competition (De Leo and Gatto 1995; Daverat et al. 2006, 2012; Drouineau et al. 2006; Edeline 2007; Geffroy and Bardonnet 2012). Regarding mean length at silvering (for males and females), a smaller size at maturity was simulated in the downstream section of the river, whereas larger lengths were occurred gradually throughout the catchment (Vollestad 1992; Oliveira 1999). 
377 and mean realized growth rate; while positive tau values pointed to an increasing trend for ratio of

378 females and mean length at silvering (Table 2).

\subsection{Model exploration}

For each combination, the 10 replicates provided the same results, confirming that the patterns were not sensitive to stochasticity. Interestingly, 310 simulations produced only females while 640 simulations produced only males. Simulations with only females corresponded to simulation where density-dependence $\alpha, L_{\infty}$ and the fecundity exponent $b$ were simultaneously strong. Conversely, simulations with only males corresponded to simulations with a low $b$ and a low $L_{\infty}$. With only one sex, it was not possible to calculate a spatial trend in sex ratio and with only males, it was not possible to calculate a trend of length at silvering.

Two questions were addressed here. In a first time, we compared the five patterns to see which of those patterns were frequently mimicked and which were less frequently mimicked. Then, we compared the sensitivity of the model to each group of parameters. To quantify this sensitivity to a group of parameters values, we compared the number of simulations that reproduce a given pattern when the group had modality (-) with the number of simulations and when the group had modality (+). A strong discrepancy indicated a high sensitivity to the group of parameters. abundance, ratio of fast growers, and mean realized growth rate were consistent with the literature in each of the 2560 combinations (Table 3). This result indicates that these model outputs do not depend on parameters values in the parameter space considered. Consequently, the assumptions about asymmetrical density-dependence and growth genotypes were enough to simulate catchment colonization. 
402 examples). This meant that, in situations where some females were produced, the pattern was 403 consistent in about $2 / 3$ of the simulations. Length at silvering pattern appeared to be sensitive to 404 most of the parameters. The two most important were $L_{\infty}$ and $b$ : consistent pattern were much more 405 frequent with a modality (+) (respectively 990 and 940 simulations) for these two parameters than 406 with modality (-) (respectively 310 and 360 simulations). This is not surprising since with modality (-) 407 for those parameters, the model produced only males in 640 simulations. Two other groups of 408 parameters had a strong influence: male fertility/ male length at silvering and density-dependence. Consistent patterns were more frequent with low male fertility and length at silvering (800 with modality (-) vs 500 with modality (+)), and with limited density dependence (810 with modality (-) vs 490 with modality $(+))$. simulations for which it was possible to calculate a pattern (Table 3). This pattern was mostly sensitive to four groups of parameters which correspond to the four most influential groups for the pattern of length at silvering. Patterns were consistent only when male fertility/length at silvering had modality (-) whereas Kslow/Mslow had modality (+). Moreover, consistent patterns were more frequent when $L_{\infty}$ had a modality $(-)$ and $b$ a modality $(+)$. the five patterns (Table 4, Figure 4 and Table S1). These 130 simulations corresponded exactly to the 130 simulations that produced consistent sex ratio patterns, demonstrating that this last pattern was

421 the more constraining (Figure 5). Consequently, the interpretation regarding sensitive parameters 422 was similar.

423 To make a summary of those results: in situations where females' fitness was favoured 424 because of a strong $L_{\infty}$ or a strong $b$, i.e. a high fecundity, the model produced only females. 425 Conversely, when females were too penalised, model produced only males. Therefore, an equilibrim 426 was required between males and females fitnesses to mimic all patterns. The patterns in length at 427 silvering and sex ratio were the two most constraining patterns and were mainly sensitive to 4 
428 groups of patterns. These groups of parameters set the equilibrium between males and females

429 fitnesses (male fertility and length at silvering, $b$ and $L_{\infty}$ ) and the advantages between slow and fast

430 growers. Density-dependence was also important regarding the pattern on length at silvering. We

431 cab observed that the five patterns were consistent mostly when slow growers and females were not

432 too penalized with respect to males and fast-growers.

433 Some of the patterns were indeed very constrained by model assumptions so it is hardly

434 surprising that they were mimicked by the model. For example, our constraints on mortality and

435 growth really constrained the distribution of fishes and probably the pattern of realised growth rates

436 in the catchment. However, those constraints were based on various observations in the literature

437 that have rarely been considered together to see if they make sense in a context of adaptive

438 response. We do not specify any constraints on the sex ratio, length at maturity and relationships

439 between sex ratio and slow/fast growers. Those results are really emerging patterns that are 440 consistent with the literature.

441

\section{Discussion}

4435.1 Adaptation to environmental variability: phenotypic plasticity and genetic polymorphism of European eel

The European eels, and more generally, temperate eels, display fascinating characteristics:

catadromy with a long larval drift, large distribution area with contrasted growth habitats, panmixia,

and strong phenotypic and tactic variability at different spatial scales. Consequently, this species is

relevant to explore adaptive mechanisms to environmental variability. Phenotypic plasticity has been 
452 phenotypic plasticity in both life-history traits and tactical choices as an adaptive response to 453 spatially structured environments and density dependence. However, recently Gagnaire et al. (2012), 454 Pujolar et al. (2014), Boivin et al. (2015), Côté et al. (2015) and Pavey et al. (2015) demonstrated the 455 existence of genetic differences correlated with the environment, suggesting that part of the 456 observed phenotypic variability had a genetic basis. Based on the approach developed by Drouineau et al. (2014), the objective of this study was to propose a model based on life-history theory and optimal foraging theory to explore the role of both adaptive phenotypic plasticity and genetic polymorphism with genetic-dependent habitat selection, in the emergence of phenotypic patterns. To that end, we used a pattern-oriented modelling approach, as developed by Grimm et al. (1996). This kind of approach compared field observed patterns to simulated patterns and postulated that those patterns are similar, the model is likely to contain the mechanisms generating these patterns.

\subsection{In which conditions were the patterns mimicked?}

Similarly to Eveel, a main limitation of our approach was that it was based on a simulation model with a pattern-oriented approach. Consequently, our results demonstrated that our assumptions were plausible, but did not demonstrate that they were correct. Such a demonstration would require demonstrating underlying mechanisms, for example by conducting complementary controlled experiments.

We built a full experimental design to explore the model. This type of approach is classical in complex model exploration (de Castro et al. 2001, Faivre et al. 2013). For example, in the context of sensitivity analysis of complex simulation models (Drouineau et al. 2006). Our exploration goals were to generate simulations from the parameter space and analyze the qualitative differences in the model output to (i) study the impact of parameters on the model output, (ii) determine which 
476 mimic all observed spatial patterns. In this study, 17 parameters grouped in 12 set of parameters,

477 were chosen to define the region of the parameter space where all spatial patterns were reproduced.

478 To assess the influence of stochasticity, we made 10 replicates per combination. This can

479 appear limited, however, it was impossible to increase the number of simulations and we preferred

480 to have a better exploration of uncertainty due to uncertain parameters rather than on stochasticity

481 which is rather limited in our model. Stochasticity occurs during the initialization process when

482 randomly building slow or fast value with a given probability. This corresponds to a binomial

483 distribution which has, given the large number of individuals, a very small variance. Stochasticity also

484 occurs in the order of individuals for step 1, but this is closely linked to the previous process and

485 consequently also has a limited variability. This limited effect of stochasticity was confirmed by our

486 results since patterns per combination were always consistent among replicates (figure 4 and 5).

487 One hundred thirty simulations among the 2560 mimicked the five spatial patterns. The

488 fourth pattern stated that fast growers and slow growers had different spatial distributions. Fulfilling

489 this pattern demonstrated that genetically different individuals have different habitat selection

490 strategies to maximize their respective fitnesses. Consequently, fulfilling the five patterns suggested

491 that, at least in certain conditions, genotype-dependent habitat selection and phenotypic plasticity

492 could explain observed phenotypic patterns. The level of sensitivity was variable among groups of

493 parameters, but four main groups of parameters were crucial: males' fertility and length at silvering,

494 growth and mortality rates of slow growers, fecundity, and $L_{\infty}$. Density-dependence was also an

495 important parameter regarding length at silvering. In summary, the patterns were mimicked in

496 simulations with dominants and dominated but when dominated individuals, mainly females, were

497 not too penalized with respect to dominants, mainly males.

498 Regarding the spatial patterns, higher density, higher proportions of fast growers, and faster

499 growth rates in downstream regions were mimicked for all combinations of parameters. This

500 suggested that in the range of variation considered, none of the parameters had effects on model

501 outputs. This probably means that the gradient in environmental conditions and the population 
502 dynamics in the model were sufficient to reproduce these patterns, regardless of the competitive 503 advantage of fast growers with respect to slow growers, confirming that phenotypic plasticity plays 504 an important role in environmentally induced changes in life-history traits and demographic 505 attributes. Concerning the two other patterns (sex ratio and length at silvering), additional 506 hypotheses are needed regarding competition and genetic polymorphism. They were fulfilled in 507 conditions of weak competition and when growth differences were not too strong between the two 508 genotypes.

\subsection{Consequences with respect to intra-specific competition}

In our model, we assumed the existence of asymmetrical density dependence between fast and slow growers. We assumed that smaller individuals would avoid engaging in competition with larger ones (regardless of sex) and would consequently be more affected by density dependence. This assumption seems ecologically realistic. Asymmetrical density dependence has been observed in plants (Weiner 1990), insects (Varley et al. 1973), and fish (Dings Ør et al. 2007). Intraspecific competition is a very common mechanism of density dependence, favoring large body size in fishes (Francis 1983; Juanes et al. 2002). In anguillid eels, this may be manifested through agonistic

517 interactions (Knights 1987; Bardonnet et al. 2005), including cannibalism (Edeline and Elie 2004). 518 Such behaviors have been observed in yellow eels under artificial rearing conditions (Peters et al. 1980; Degani and Levanon 1983; Knights 1987).

520 We modelled this asymmetric competition by specifying different levels of density521 dependent mortality for slow and fast growers. Interestingly, the spatial patterns were still 522 reproduced when setting these parameters to a similar value (not presented here). Indeed, even with 523 similar intensity of density dependence, slow growers needed more time to reach their length at 524 silvering and consequently, suffered competition longer. Thus, even if competition has the same 525 impact on instantaneous mortality rates of slow and fast-growers, density dependence produces 526 asymmetric impacts on their respective fitness. In EvEel, Drouineau et al. (2014) assumed the 
527 existence of asymmetric competition between males and females, with females being more affected

528 by competition. Interestingly, we observed in our results that females had a higher proportion of

529 slow growers than males. This means that the gender-based asymmetry proposed by Drouineau et al.

530 (2014) may be an indirect result of an asymmetry between two genetically distinct types of

531 individuals with respect to growth.

532 The asymmetric competition implies that fitness of individuals having a given growth

533 genotype depends on the number of individuals having the other growth genotype, which may lead

534 to frequency-dependent selection (Heino et al. 1998). This has several implications. In the model, we

535 assumed that individual fitness corresponded to the lifetime reproductive success called R0, and that

536 this fitness is maximized. However, in a frequency-dependent selection context (i) natural selection

537 does not necessarily lead in fitness maximization (Mylius and Diekmann 1995; Metz et al. 2008) and,

538 (ii) fitness may need to be defined as an invasion criterion (Metz et al. 1992). Even when fitness

539 maximisation applies, $r$, the population growth rate, may be a more appropriate measure of fitness

540 than R0 depending on how density-dependence acts (Mylius and Diekmann 1995). To ensure that

541 our assumptions about fitness definition and maximization were valid would require a multi-

542 generational model at the scale of the population distribution area. This would allow computing

543 fitness for the whole life-cycle across all potential habitat types of the distribution area while

544 accounting for population structure in terms of genotypes or clusters. At this point, it would be

545 interesting to explore the heritability of the different traits and the intra-generational spatially

546 varying selection, a mechanism suggested by the SNP differences reported by (Pujolar et al. 2011;

547 Gagnaire et al. 2012; Ulrik et al. 2014), according to latitude. This was not possible because of

548 difficulties to develop a whole life-cycle model. More specifically, the fractal dimension of the eel

549 population makes it very difficult to develop a population dynamics model for the continental phase

550 at the distribution area scale. Moreover, such a model would require the use of stock-recruitment

551 relationships, which is very difficult for the European eels because of insufficient data, long larval

552 drift, and different recruitment trends through the distribution area. In this context, we had to use 
553 intra-generational model and a R0 fitness function, restricted to a single catchment and a portion of 554 the whole life-cycle, and to postulate that this R0 was maximised.

\subsection{Reinterpreting the time-minimizing and size-maximizing strategies}

To summarize the results for combinations of parameters that mimicked observed patterns,

557 we observed a high proportion of individuals, mainly fast growers, in the downstream environment, 558 which corresponded to marine or brackish water. These individuals were mainly males with a 559 constant length at silvering. In upstream areas, we found mainly slow growers, primarily females with 560 higher length at silvering. This can aid in the reinterpretation of gender difference in life tactics (i.e., 561 males with a time-maximizing strategy and females with a size-maximizing strategy). Our results 562 suggest that these tactics were possibly based on the existence of two genotypes for growth. Fast growers grow fast but suffer higher mortality (because they inhabit downstream habitats with higher mortality and density); a time-minimizing strategy is suitable for them. Slow growers grow slowly but suffer lower mortality, consequently they can stay longer in continental habitats, and a sizemaximizing strategy is suitable for them.

Another interesting question is whether cues are used by individuals to select their growth habitat. In the model, individuals were omnipotent and omniscient: they were able to assess the potential fitness in each cell and move in the most suitable cell. This would mean that they were able to assess the natural mortality, growth rate, and density in each cell. Drouineau et al. (2014)

571 suggested that temperature might be one of the main proximal cue used by individuals to assess the 572 suitability. Regarding density-dependence, reaction to aggressiveness (Geffroy and Bardonnet, 2012)

573 or cons-specific odors (Schmucker et al. 2016) have been were observed on growth and propensity

574 to migrate. Vélez-Espino and Koops (2010) also revealed temperature as main factor explaining 575 variation in life-history traits. Our model suggested that density in various habitats was also probably 576 a main cue, especially for slow growers, which tended to minimize competition. 


\section{$577 \quad 5.5$ Perspectives}

578

579

580

581

582

583

584

585

586

587

588

589

590

591

592

593

594

595

596

597

598

\subsubsection{Exploring conditions in which phenotypic plasticity is adaptive}

It has been demonstrated that phenotypic plasticity allows short-term adaptation to environmental heterogeneity for many species (Schlichting 1986; Sultan 1987; Scheiner 1993; Pigliucci 2005). However, the fitness gain arising from phenotypic plasticity should overcome its cost to be selected. This last point has not been demonstrated for eels. One possibility would be to simulate the evolution of a plastic reaction norm, for example length at silvering, close to the model developed by Marty et al. (2011). Following Ernande et al. (2004) and based on adaptive dynamics models Mylius and Diekmann (1995), it would be interesting to explore in which environmental and density-dependence conditions, phenotypic plasticity may be selected as an adaptive mechanism despite its costs, and if plasticity is still adaptive in a context of low densities after a population collapse.

\subsubsection{Assessing the impact of anthropogenic pressures at the distribution area scale}

Another perspective is to assess the impact of anthropogenic pressures on eel populations. Drouineau et al. (2014) mentioned that, because of phenotypic plasticity, anthropogenic pressures are not only a source of mortality, but may also affect sex ratio or mean length at silvering. The existence of two genotypes for growth suggests that anthropogenic activities may act as selective forces. Recently, Podgorniak et al. (2015) demonstrated that human-induced obstacles to migration could act as an evolutionary pressure. Concerning this, Boulenger et al. (2016) highlighted that human pressures impact survival, leading to different life-history strategies. 
599 To conclude, our model provided new insights on eel adaptive mechanisms to heterogeneous 600 environments. Phenotypic plasticity and genotype-dependent habitat selection are two types of 601 mechanisms that can explain the patterns in life-history traits observed in natural environments at 602 the river catchment scale. A better understanding of these mechanisms is crucial to interpret the 603 observations made in the environment, the effects of anthropogenic pressures on the population, 604 and to understand if eels are still adapted in the context of depleted population size and climate 605 change.

606

\section{Acknowledgements}

This study was supported by the Hynes project between Irstea and EDF R\&D. We would like to thank Christian Rigaud and Laurent Beaulaton and two anonymous referees for their contribution 610 to the discussion.

611

\section{References}

Acou, A., Lefebvre, F., Contournet, P., Poizat, G., Panfili, J., and Crivelli, A.J. 2003. Silvering of female

Bardonnet, A., Rigaud, C., and Labonne, J. 2005. Etude expérimentale des comportements de civelles eels (Anguilla anguilla) in two sub-populations of the Rhone Delta. Bull. Fr. Pêche Piscic. 368: $55-68$.

Als, T.D., Hansen, M.M., Maes, G.E., Castonguay, M., Riemann, L., Aarestrup, K., Munk, P., Sparholt, H., Hanel, R., and Bernatchez, L. 2011. All roads lead to home: panmixia of European eel in the Sargasso Sea. Mol. Ecol. 20(7): 1333-1346. doi:10.1111/j.1365-294X.2011.05011.x.

Andrello, M., Bevacqua, D., Maes, G.E., and De Leo, G.A. 2011. An integrated genetic-demographic model to unravel the origin of genetic structure in European eel (Anguilla anguilla L.): Genetic-demographic model for the European eel. Evol. Appl. 4(4): 517-533. doi:10.1111/j.1752-4571.2010.00167.x. d'Anguilla anguilla $\mathrm{L}$. influence de la densité et de la disponibilité en abris. Bull. Fr. Pêche Piscic. 378-379: 47-65. 
626 Bevacqua, D., Melià, P., De Leo, G.A., and Gatto, M. 2011. Intra-specific scaling of natural mortality in 627 fish: the paradigmatic case of the European eel. Oecologia 165(2): 333-339.

628

629

630

631

632

633

634

635

636

637

638

639

640

641

642

643

644

645

646

647

648

649

650

651

652

653

654

655

656

657

658 doi:10.1007/s00442-010-1727-9.

Boivin, B., Castonguay, M., Audet, C., Pavey, S.A., Dionne, M., and Bernatchez, L. 2015. How does salinity influence habitat selection and growth in juvenile American eels Anguilla rostrata?: salinity preference in Anguilla rostrata glass eels. J. Fish Biol. 86(2): 765-784. doi:10.1111/jfb.12604.

Boulenger, C., Acou, A., Gimenez, O., Charrier, F., Tremblay, J., and Feunteun, E. 2016. Factors determining survival of European eels in two unexploited sub-populations. Freshw. Biol. 61(6): 947-962. doi:10.1111/fwb.12759.

Brodersen, J., and Seehausen, O. 2014. Why evolutionary biologists should get seriously involved in ecological monitoring and applied biodiversity assessment programs. Evol. Appl. 7(9): 968983. doi:10.1111/eva.12215.

Cairns, D.K., Secor, D.A., Morrison, W.E., and Hallett, J.A. 2009. Salinity-linked growth in anguillid eels and the paradox of temperate-zone catadromy. J. Fish Biol. 74(9): 2094-2114. doi:10.1111/j.1095-8649.2009.02290.x.

de Castro, L.A.B., Petrere Jr., M., and Comune, A.E. 2001. Sensitivity of the BEAM4 fisheries bioeconomic model to the main biological input parameters. Ecol. Model. 141(1-3): 53-66. doi:10.1016/S0304-3800(01)00241-1.

Clark, C.W. 1993. Dynamic Models of Behavior: An extension of Life-history Theory. Tree 8(6): 205209.

Côté, C.L., Castonguay, M., Kalujnaia, M., Cramb, G., and Bernatchez, L. 2014. In absence of local adaptation, plasticity and spatially varying selection rule: a view from genomic reaction norms in a panmictic species (Anguilla rostrata). BMC Genomics 15(1): 403. doi:10.1186/1471-2164-15-403.

Côté, C.L., Castonguay, M., Verreault, G., and Bernatchez, L. 2009. Differential effects of origin and salinity rearing conditions on growth of glass eels of the American eel Anguilla rostrata: implications for stocking programmes. J. Fish Biol. 74(9): 1934-1948. doi:10.1111/j.10958649.2009.02291.x.

Côté, C.L., Gagnaire, P.-A., Bourret, V., Verreault, G., Castonguay, M., and Bernatchez, L. 2013. Population genetics of the American eel (Anguilla rostrata): $F_{\text {ST }}=0$ and North Atlantic Oscillation effects on demographic fluctuations of a panmictic species. Mol. Ecol. 22(7): 1763-1776. doi:10.1111/mec.12142. 
659 Côté, C.L., Pavey, S.A., Stacey, J.A., Pratt, T.C., Castonguay, M., Audet, C., and Bernatchez, L. 2015. 660 Growth, Female Size, and Sex Ratio Variability in American Eel of Different Origins in Both

661

662

663

664

665

666

667

668

669

670

671

672

673

674

675

676

677

678

679

680

681

682

683

684

685

686

687

688

689

690

691

692 Controlled Conditions and the Wild: Implications for Stocking Programs. Trans. Am. Fish. Soc. 144(2): 246-257. doi:10.1080/00028487.2014.975841.

Council of the European Union. 2007. Council Regulation (EC) No 1100/2007 of 18 September 2007 establishing measures for the recovery of the stock of European eel. Brussels: 7pp.

Daverat, F., Beaulaton, L., Poole, R., Lambert, P., Wickström, H., Andersson, J., Aprahamian, M., Hizem, B., Elie, P., Yalçın-Özdilek, S., and Gumus, A. 2012. One century of eel growth: changes and implications. Ecol. Freshw. Fish 21(3): 325-336. doi:10.1111/j.1600-0633.2011.00541.x.

Daverat, F., Limburg, K.E., Thibault, I., Shiao, J.-C., Dodson, J.J., Caron, F., Tzeng, W.-N., lizuka, Y., and Wickstrom, H. 2006. Phenotypic plasticity of habitat use by three temperate eel species, Anguilla anguilla, A. japonica and A. rostrata. Mar. Ecol. Prog. Ser. 308: 231-241.

Daverat, F., and Tomás, J. 2006. Tactics and demographic attributes in the European eel Anguilla anguilla in the Gironde watershed, SW France. Mar. Ecol.-Prog. Ser. 307: p-247.

Davey, A.J.H., and Jellyman, D.J. 2005. Sex Determination in Freshwater Eels and Management Options for Manipulation of Sex. Rev. Fish Biol. Fish. 15(1-2): 37-52. doi:10.1007/s11160005-7431-x.

De Leo, G.A., and Gatto, M. 1995. A size and age-structured model of the European eel (Anguilla anguilla L.). Can. J. Fish. Aquat. Sci. 52: 1351-1367.

Degani, G., and Levanon, D. 1983. The influence of low density on food adaptation, cannibalism and growth of eels (Anguilla anguilla (L.)). Bamidgeh 35: 53-60.

Dekker, W. 1998. Long-term trends in the glass eels immigrating at Den Oever, The Netherlands. Bull. Fr. Pêche Piscic. (349): 199-214. doi:10.1051/kmae:1998045.

Dekker, W. 2000. The fractal geometry of the European eel stock. ICES J. Mar. Sci. 57(1): 109-121. doi:10.1006/jmsc.1999.0562.

Dekker, W. 2003. Status of the European Eel Stock and Fisheries. In Eel Biology. Edited by K. Aida, K. Tsukamoto, and K. Yamauchi. Springer Japan. pp. 237-254.

Dekker, W. 2009. Worldwide decline of eel resources necessitates immediate action.

Desaunay, Y., and Guerault, D. 1997. Seasonal and long-term changes in biometrics of eel larvae: a possible relationship between recruitment variation and North Atlantic ecosystem productivity. J. Fish Biol. 51(sA): 317-339.

Desaunay, Y., Lecomte-Finiger, R., and Guérault, D. 2012. Mean age and migration patterns of Anguilla anguilla (L.) glass eels from three French estuaries (Somme, Vilaine and Adour Rivers). Arch. Pol. Fish. 20(3). doi:10.2478/v10086-012-0023-1. 
693 Dings $\varnothing$ r, G.E., Ciannelli, L., Chan, K.-S., Ottersen, G., and Stenseth, N.C. 2007. Density dependence

694

695

696

697

698

699

700

701

702

703

704

705

706

707

708

709

710

711

712

713

714

715

716

717

718

719

720

721

722

723

724

725

726 and density independence during the early life stages of four marine fish stocks. Ecology 88(3): 625-634.

Drouineau, H., Mahévas, S., Pelletier, D., and Beliaeff, B. 2006. Assessing the impact of different management options using ISIS-Fish: the French Merluccius merluccius - Nephrops norvegicus mixed fishery of the Bay of Biscay. Aquat. Living Resour. 19(1): 15-29. doi:10.1051/alr:2006002.

Drouineau, H., Rigaud, C., Daverat, F. and Lambert, P. 2014. EvEel (evolutionary ecology-based model for eel): a model to explore the role of phenotypic plasticity as an adaptive response of three temperate eels to spatially structured environments. Can. J. Fish. Aquat. Sci. 71(10): 15611571. doi:10.1139/cjfas-2014-0090.

Edeline, E. 2007. Adaptive phenotypic plasticity of eel diadromy. Mar. Ecol. Prog. Ser. 341: 229-232.

Edeline, E., and Elie, P. 2004. Is salinity choice related to growth in juvenile eel Anguilla anguilla? Cybium 28: 77-82.

Ernande, B., Dieckmann, U., and Heino, M. 2004. Adaptive changes in harvested populations: plasticity and evolution of age and size at maturation. Proc. R. Soc. Lond. B Biol. Sci. 271(1537): 415-423.

Faivre, R., looss, B., Mahévas, S., Makowski, D., and Monod, H. 2013. Analyse de sensibilité et exploration de modèles. Editions Quae.

Francis, R.C. 1983. Experiential effects on agonistic behavior in the paradise fish, Macropodus opercularis. Behaviour 85(3): 292-313.

Gagnaire, P.-A., Normandeau, E., Cote, C., Moller Hansen, M., and Bernatchez, L. 2012. The Genetic Consequences of Spatially Varying Selection in the Panmictic American Eel (Anguilla rostrata). Genetics 190(2): 725-736. doi:10.1534/genetics.111.134825.

Geffroy, B., and Bardonnet, A. 2012. Differential effects of behaviour, propensity to migrate and recruitment season on glass eels and elvers' growing performance: Young eel behaviour and growth pattern. Ecol. Freshw. Fish 21(3): 469-482. doi:10.1111/j.1600-0633.2012.00566.x.

Giske, J., Huse, G., and Fiksen, O. 1998. Modelling spatial dynamics of fish. Rev. Fish Biol. Fish. 8: 5791. doi:10.1023/A:1008864517488.

Gotthard, K., and Nylin, S. 1995. Adaptive plasticity and plasticity as an adaptation: a selective review of plasticity in animal morphology and life-history. Oikos 74(1): 3-17. doi:10.2307/3545669.

Grimm, V., Berger, U., Bastiansen, F., Eliassen, S., Ginot, V., Giske, J., Goss-Custard, J., Grand, T., Heinz, S.K., Huse, G., Huth, A., Jepsen, J.U., Jørgensen, C., Mooij, W.M., Müller, B., Pe'er, G., Piou, C., Railsback, S.F., Robbins, A.M., Robbins, M.M., Rossmanith, E., Rüger, N., Strand, E., Souissi, S., 
727

728

729

730

731

732

733

734

735

736

737

738

739

740

741

742

743

744

745

746

747

748

749

750

751

752

753

754

755

756

757

758

759

Stillman, R.A., Vabø, R., Visser, U., and DeAngelis, D.L. 2006. A standard protocol for describing individual-based and agent-based models. Ecol. Model. 198(1-2): 115-126. doi:10.1016/j.ecolmodel.2006.04.023.

Grimm, V., Berger, U., DeAngelis, D.L., Polhill, J.G., Giske, J., and Railsback, S.F. 2010. The ODD protocol: A review and first update. Ecol. Model. 221(23): 2760-2768. doi:10.1016/j.ecolmodel.2010.08.019.

Grimm, V., Frank, K., Jeltsch, F., Brandl, R., Uchmanski, J., and Wissel, C. 1996. Pattern-oriented modelling in population ecology. Sci. Total Environ. 183: 155-166.

Grimm, V., and Railsback, S.F. 2012. Pattern-oriented modelling: a "multi-scope" for predictive systems ecology. Philos. Trans. R. Soc. B Biol. Sci. 367(1586): 298-310. doi:10.1098/rstb.2011.0180.

Heino, M., Metz, J.A.J., and Kaitala, V. (1998). The enigma of frequency-dependent selection. Trends Ecol. Evol. (13): 367-370.

Helfman, G.S., Facey, D.E., Stanton Hales, L., and Bozeman, E.L. 1987. Reproductive Ecology of the American eel. Am. Fish Soc. Symp. 1: 42-56.

Hutchings, J.A., Swain, D.P., Rowe, S., Eddington, J.D., Puvanendran, V., and Brown, J.A. 2007. Genetic variation in life-history reaction norms in a marine fish. Proc. R. Soc. B Biol. Sci. 274(1619): 1693-1699. doi:10.1098/rspb.2007.0263.

Jacoby, D., and Gollock, M. 2014. Anguilla anguilla. The IUCN Red List of Threatened Species. Available from http://www.iucnredlist.org/details/60344/0.

Juanes, F., Buckel, J.A., and Scharf, F.S. 2002. Feeding ecology of piscivorous fishes. In Handbook of fish biology and fisheries, Blackwell. Paul J.B. Hart and John D. Reynolds, UK. pp. 267-283.

Kawecki, T.J., and Ebert, D. 2004. Conceptual issues in local adaptation. Ecol. Lett. 7(12): 1225-1241. doi:10.1111/j.1461-0248.2004.00684.x.

Kleijnen, J.P.C. 1987. Statistical Tools for Simulation Practitioners. Marcel Dekker, Inc., New York, NY, USA.

Knights, B. 1987. Agonistic behaviour and growth in the European eel, Anguilla anguilla L., in relation to warm-water aquaculture. J. Fish Biol. 31(2): 265-276.

Levins, R. 1963. Theory of fitness in a heterogeneous environment. II. Developmental flexibility and niche selection. Am. Nat. 97(893): 75-90. doi:10.1086/ 282258.

Marty, L., Dieckmann, U., Rochet, M.-J., and Ernande, B. 2011. Impact of Environmental Covariation in Growth and Mortality on Evolving Maturation Reaction Norms. Am. Nat. 177(4): E98E118. doi:10.1086/658988. 
760

761

762

763

764

765

766

767

768

769

770

771

772

773

774

775

776

777

778

779

780

781

782

783

784

785

786

787

788

789

790

791

792

793

McNamara, J.M., and Houston, A.I. 1992. State-dependent life-history theory and its implications for optimal clutch size. Evol. Ecol. 6(2): 170-185. doi:10.1007/BF02270710.

Melià, P., Bevacqua, D., Crivelli, A.J., De Leo, G.A., Panfili, J., and Gatto, M. 2006. Age and growth of Anguilla anguilla in the Camargue lagoons. J. Fish Biol. 68: 876-890. doi:10.1111/j.10958649.2006.00975.x.

Metz, J.A.J., Mylius, S.D., and Diekmann, O. 2008. When does evolution optimize? Evol. Ecol. Res. 10(5): 629-654.

Metz, J.A.J., Nisbet, R.M., and Geritz, S.A.H. 1992. How should we define "fitness" for general ecological scenarios? Trends Ecol. Evol. 7(6): 198-202.

Moriarty, C. 2003. The eel. In Eel Biology. Springer Japan, Tokyo. pp. 89-105.

Mylius, S.D., and Diekmann, O. 1995. On Evolutionarily Stable Life Histories, Optimization and the Need to Be Specific about Density Dependence. Oikos 74(2): 218-224.

Oliveira, K. 1999. Life-history characteristics and strategies of the American eel, Anguilla rostrata. Can. J. Fish. Aquat. Sci. 56(5): 795-802.

Oliveira, K. 2001. Regional variation and the effect of lake: river area on sex distribution of American eels. J. Fish Biol. 58(4): 943-952. doi:10.1006/jfbi.2000.1503.

Palm, S., Dannewitz, J., Prestegaard, T., and Wickström, H. 2009. Panmixia in European eel revisited: no genetic difference between maturing adults from southern and northern Europe. Heredity 103(1): 82-89.

Parker, G.A., and Maynard Smith, J. 1990. Optimality theory in evolutionary biology. Nature 348: 2733.

Pavey, S.A., Gaudin, J., Normandeau, E., Dionne, M., Castonguay, M., Audet, C., and Bernatchez, L. 2015. RAD Sequencing Highlights Polygenic Discrimination of Habitat Ecotypes in the Panmictic American Eel. Curr. Biol. 25(12): 1666-1671. doi:10.1016/j.cub.2015.04.062.

Peters, G., Delventhal, H., and Klinger, H. 1980. Physiological and Morphological Effects of Social Stress on the Eel, Anguilla anguilla L. In Fish Diseases. Edited by D.W. Ahne. Springer Berlin Heidelberg. pp. 225-227.

Pigliucci, M. 2005. Evolution of phenotypic plasticity: Where are we going now? Trends Ecol. Evol. 20(9): 481-486. doi:10.1016/j.tree.2005.06.001.

Podgorniak, T., Angelini, A., Blanchet, S., de Oliveira, E., Pierron, F., and Daverat, F. 2015. Climbing experience in glass eels: A cognitive task or a matter of physical capacities? Physiol. Behav. 151: 448-455. doi:10.1016/j.physbeh.2015.08.001.

Pujolar, J.M., Bevacqua, D., Andrello, M., Capoccioni, F., Ciccotti, E., De Leo, G.A., and Zane, L. 2011. Genetic patchiness in European eel adults evidenced by molecular genetics and population 
794

795

796

797

798

799

800

801

802

803

804

805

806

807

808

809

810

811

812

813

814

815

816

817

818

819

820

821

822

823

824

825

826

827

dynamics modelling. Mol. Phylogenet. Evol. 58(2): 198-206. doi:10.1016/j.ympev.2010.11.019.

Pujolar, J.M., Jacobsen, M.W., Als, T.D., Frydenberg, J., Munch, K., Jónsson, B., Jian, J.B., Cheng, L., Maes, G.E., Bernatchez, L., and Hansen, M.M. 2014. Genome-wide single-generation signatures of local selection in the panmictic European eel. Mol. Ecol. 23(10): 2514-2528. doi:10.1111/mec.12753.

Railsback, S.F., and Harvey, B.C. 2013. Trait-mediated trophic interactions: is foraging theory keeping up? Trends Ecol. Evol. 28(2): 119-125. doi:10.1016/j.tree.2012.08.023.

Rougier, T., Lassalle, G., Drouineau, H., Dumoulin, N., Faure, T., Deffuant, G., Rochard, E., and Lambert, P. 2015. The Combined Use of Correlative and Mechanistic Species Distribution Models Benefits Low Conservation Status Species. PLOS ONE 10(10): e0139194. doi:10.1371/journal.pone.0139194.

Scheiner, S.M. 1993. Genetics and Evolution of Phenotypic Plasticity. Annu. Rev. Ecol. Syst. 24: 35-68.

Schlichting, C.D. 1986. The Evolution of Phenotypic Plasticity in Plants. Annu. Rev. Ecol. Syst. 17(1): 667-693. doi:10.1146/annurev.es.17.110186.003315.

Sultan, S.E. 1987. Evolutionary Implications of Phenotypic Plasticity in Plants. In Evolutionary Biology. Edited by M.K. Hecht, B. Wallace, and G.T. Prance. Springer US. pp. 127-178.

Tesch, F.-W. 2003. The eel. In 3rd ed. Blackwell Science, Oxford, UK.

Travis, J. 1994. Evaluating the adaptive role of morphological plasticity. In Ecological Morphology. Edited by P. Wainwright and S. Reilly. University of Chicago Press. pp. 99-122.

Ulrik, M.G., Pujolar, J.M., Ferchaud, A.-L., Jacobsen, M.W., Als, T.D., Gagnaire, P.A., Frydenberg, J., Bøcher, P.K., Jónsson, B., Bernatchez, L., and others. 2014. Do North Atlantic eels show parallel patterns of spatially varying selection? BMC Evol. Biol. 14(1): 138.

Varley, C.G., Gradwell, G.R., and Hassell, M.P. 1973. Insect population ecology an analytical approach. University of California Press, California.

Vélez-Espino, L.A., and Koops, M.A. 2010. A synthesis of the ecological processes influencing variation in life-history and movement patterns of American eel: towards a global assessment. Rev. Fish Biol. Fish. 20(2): 163-186. doi:10.1007/s11160-009-9127-0.

Vollestad, L.A. 1992. Geographic Variation in Age and Length at Metamorphosis of Maturing European Eel: Ennvironmental Effects and Phenotypic Plasticity. J. Anim. Ecol. 61(1): 41-48.

Weiner, J. 1990. Asymmertic Competition in Plant Population. Tree 5(11): 360-364.

Williams, G.C. 1996. Adaptation and natural selection: a critique of some current evolutionary thought. Princeton Univ. Press, Princeton, NJ. 


\section{Tables}

829 Table 1. GenEveel parameter descriptions with reference values and modalities (- and + ) for the 17 830 parameters involved in the experimental design.

\begin{tabular}{|c|c|c|c|c|c|}
\hline Parameter & Description & $\begin{array}{c}\text { Reference } \\
\text { value }\end{array}$ & $\begin{array}{c}(-) \\
\text { modality }\end{array}$ & $\begin{array}{c}(+) \\
\text { modality }\end{array}$ & Reference \\
\hline$n$ & Cells of river catchment & 30 & 24 & 36 & (Drouineau et al. 2014) \\
\hline$N$ & $\begin{array}{l}\text { Number of glass eels that } \\
\text { colonize freshwater }\end{array}$ & 30000 & 24000 & 36000 & (Drouineau et al. 2014) \\
\hline$a 1$ & $\begin{array}{l}\text { Regression coefficient from } \\
\text { fecundity at length }\end{array}$ & 8846 & - & - & (Andrello et al. 2011) \\
\hline$a$ & $\begin{array}{l}\text { Regression coefficient from } \\
\text { fecundity at length }\end{array}$ & 1.3877119 & - & - & $\begin{array}{c}\text { (Melià et al. 2006, Andrello } \\
\text { et al. 2011) }\end{array}$ \\
\hline$b$ & $\begin{array}{l}\text { Regression exponent from } \\
\text { fecundity at length }\end{array}$ & 3.22 & 2.576 & 3.864 & (Melià et al. 2006) \\
\hline$L_{\infty}(\mathrm{cm})$ & Asymptotic length & 76.2 & 60.96 & 91.44 & (De Leo and Gatto 1995) \\
\hline$L_{s m}(\mathrm{~cm})$ & Male length at silvering & 40.5 & 38.15 & 42.85 & $\begin{array}{c}\text { (Vollestad 1992) } \\
\text { (Desaunay and Guerault }\end{array}$ \\
\hline$L_{g}(\mathrm{~cm})$ & Length at recruitment & 7.5 & 6 & 9 & $\begin{array}{l}\text { 1997, Dekker 1998, } \\
\text { Desaunay et al. 2012) }\end{array}$ \\
\hline fertility & Constant of male fertility & 43 & 40.5 & 45.5 & - \\
\hline$K_{\text {fast }}(i, 1)$, year $^{-1}$ & Fast intrinsic growth rate & 0.315 & 0.295 & 0.335 & (De Leo and Gatto 1995) \\
\hline$K_{\text {slow }}(i, 1)$, year $^{-1}$ & Slow intrinsic growth rate & 0.253 & 0.233 & 0.273 & (De Leo and Gatto 1995) \\
\hline propk & $\begin{array}{l}\text { Proportion of individuals } \\
\text { that grow slowly }\end{array}$ & 0.5 & 0.4 & 0.6 & - \\
\hline$M_{\text {fast }}(i, 1)$, year $^{-1}$ & Fast intrinsic mortality rate & 0.38 & 0.405 & 0.355 & - \\
\hline$M_{\text {slow }}(i, 1)$, year ${ }^{-1}$ & Slow intrinsic mortality rate & 0.138 & 0.15 & 0.127 & (Dekker 2000) \\
\hline$\alpha$ & $\begin{array}{l}\text { Intensity of density- } \\
\text { dependence }\end{array}$ & 0.0001 & 0.00008 & 0.00012 & (Drouineau et al. 2014) \\
\hline$r_{k}$ & $\begin{array}{l}\text { Ratio between upstream } \\
\text { and downstream growth } \\
\text { rate }\end{array}$ & 0.5 & 0.4 & 0.6 & (Drouineau et al. 2014) \\
\hline$r_{M}$ & $\begin{array}{l}\text { Ratio between upstream } \\
\text { and downstream mortality }\end{array}$ & 1 & 0.8 & 1.02 & (Drouineau et al. 2014) \\
\hline
\end{tabular}




\begin{tabular}{ccccc}
\multicolumn{9}{c}{$\begin{array}{c}\text { rate } \\
Y_{K}\end{array} \quad \begin{array}{c}\text { Shape parameter of growth } \\
\text { Shape parameter of }\end{array}$} & 0.05 & 0.049 & 0.051 & (Drouineau et al. 2014) \\
$Y_{M}$ & 0.05 & 0.049 & 0.051 & (Drouineau et al. 2014)
\end{tabular}

831 
832 Table 2. Results of Mann-Kendall test of reference simulation.

\begin{tabular}{cc}
\hline Spatial pattern & Tau \\
\hline Abundance & -1 \\
Mean length at silvering & 0.98 \\
Sex ratio (proportion of females) & 0.57 \\
Ratio of fast growers & -0.78 \\
Mean realized growth rate & -1 \\
\hline
\end{tabular}

833 
834 Table 3. Number of simulations with consistent patterns for each modality of the groups of 835 parameters, over the number of simulations for which it was possible to calculate a pattern. The 836 columns represent the spatial patterns and the numbers of simulations for which it was possible to 837 estimate a pattern.

\begin{tabular}{|c|c|c|c|c|c|c|}
\hline $\begin{array}{l}\text { Parameters } \\
\text { group }\end{array}$ & $\begin{array}{c}\text { Abundance } \\
2560\end{array}$ & $\begin{array}{c}\text { Mean length } \\
\text { at silvering } \\
1920\end{array}$ & $\begin{array}{c}\text { Sex ratio } \\
\text { (proportion } \\
\text { of females) } \\
1610\end{array}$ & $\begin{array}{c}\text { Ratio of fast } \\
\text { growers } \\
2560\end{array}$ & $\begin{array}{c}\text { Mean } \\
\text { realized } \\
\text { growth rate } \\
2560\end{array}$ & $\begin{array}{c}\text { The five } \\
\text { spatial } \\
\text { patterns } \\
1610\end{array}$ \\
\hline \multirow{2}{*}{$N$} & (-) 1280/1280 & (-) 650/960 & (-) 70/800 & (-) 1280/1280 & (-) 1280/1280 & (-) 70/800 \\
\hline & (+) 1280/1280 & (+) 650/960 & (+) 60/810 & (+) 1280/1280 & (+) 1280/1280 & $(+) 60 / 810$ \\
\hline fertility and & $(-)$ 1280/1280 & $(-)$ 800/960 & (-) 130/800 & (-) 1280/1280 & (-) 1280/1280 & $(-) 130 / 800$ \\
\hline$L_{s m}$ & (+) 1280/1280 & (+) 500/960 & $(+)$ 0/810 & (+) 1280/1280 & (+) 1280/1280 & (+) 0/810 \\
\hline$K_{\text {fast }}(i, 1)$ and & $(-)$ 1280/1280 & (-) 650/960 & (-) 70/810 & (-) 1280/1280 & (-) $1280 / 1280$ & $(-) 70 / 810$ \\
\hline$M_{\text {fast }}(i, 1)$ & (+) 1280/1280 & (+) 650/960 & (+) 60/800 & (+) 1280/1280 & (+) 1280/1280 & (+) 60/800 \\
\hline $\boldsymbol{K}_{\text {slow }}(i, 1)$ and & (-) 1280/1280 & (-) 710/960 & (-) 0/810 & (-) 1280/1280 & (-) 1280/1280 & $(-)$ 0/810 \\
\hline$M_{\text {slow }}(i, 1)$ & (+) 1280/1280 & (+) 590/960 & (+) 130/800 & (+) 1280/1280 & (+) 1280/1280 & (+) 130/800 \\
\hline \multirow{2}{*}{ propK } & (-) 1280/1280 & (-) 650/960 & (-) 90/810 & (-) 1280/1280 & (-) 1280/1280 & (-) 90/810 \\
\hline & (+) 1280/1280 & (+) 650/960 & (+) 40/800 & (+) 1280/1280 & $(+) 1280 / 1280$ & (+) 40/800 \\
\hline \multirow{2}{*}{$\alpha$} & (-) 1280/1280 & & (-) 60/960 & (-) 1280/1280 & $(-)$ 1280/1280 & (-) 60/960 \\
\hline & (+) 1280/1280 & (+) 490/960 & (+) 70/650 & (+) 1280/1280 & (+) 1280/1280 & (+) 70/650 \\
\hline \multirow{2}{*}{$n$} & $(-)$ 1280/1280 & $(-)$ 660/960 & (-) 60/810 & $(-)$ 1280/1280 & $(-)$ 1280/1280 & $(-)$ 60/810 \\
\hline & (+) 1280/1280 & (+) 640/960 & (+) 70/800 & (+) 1280/1280 & (+) 1280/1280 & (+) 70/800 \\
\hline \multirow[t]{2}{*}{$\boldsymbol{b}$} & & & & & (-) 1280/1280 & (-) $10 / 640$ \\
\hline & (+) 1280/1280 & $(+)$ 940/1280 & (+) 120/970 & (+) 1280/1280 & (+) 1280/1280 & (+) 120/970 \\
\hline \multirow{2}{*}{$L_{\infty}$} & (-) 1280/1280 & $(-)$ 310/640 & (-) 120/640 & (-) 1280/1280 & (-) 1280/1280 & (-) 120/640 \\
\hline & (+) 1280/1280 & $(+)$ 990/1280 & (+) 10/970 & (+) 1280/1280 & $(+)$ 1280/1280 & (+) 10/970 \\
\hline \multirow{2}{*}{$L_{g}$} & (-) 1280/1280 & (-) 650/960 & $(-)$ 60/800 & $(-)$ 1280/1280 & (-) 1280/1280 & $(-) 60 / 800$ \\
\hline & (+) 1280/1280 & (+) 650/960 & (+) 70/810 & (+) 1280/1280 & $(+) 1280 / 1280$ & (+) 70/810 \\
\hline \multirow{2}{*}{$\boldsymbol{r}_{k}$ and $\boldsymbol{r}_{\boldsymbol{m}}$} & $(-)$ 1280/1280 & (-) 630/960 & (-) 40/810 & $(-)$ 1280/1280 & (-) 1280/1280 & (-) 40/810 \\
\hline & (+) 1280/1280 & (+) 670/960 & (+) 90/800 & (+) 1280/1280 & (+) 1280/1280 & (+) 90/800 \\
\hline \multirow{2}{*}{$\gamma_{k}$ and $\gamma_{m}$} & (-) 1280/1280 & $(-)$ 730/960 & $(-)$ 60/810 & (-) 1280/1280 & (-) $1280 / 1280$ & $(-) 60 / 810$ \\
\hline & (+) 1280/1280 & (+) 570/960 & (+) 70/800 & $(+) 1280 / 1280$ & (+) 1280/1280 & $(+)$ 70/800 \\
\hline
\end{tabular}


838 Table 4. Results of the 13 combinations that generated five consistent patterns. The signs $+/$ - refer to

839 the modalities of the parameters groups. The two last columns represent the five spatial patterns. An

840 ascendant arrows stands for positive Mann-Kendall tau value (increasing trend from downstream to

841 upstream). Conversely, a descendant arrow stands for a negative Mann-Kendall tau value.

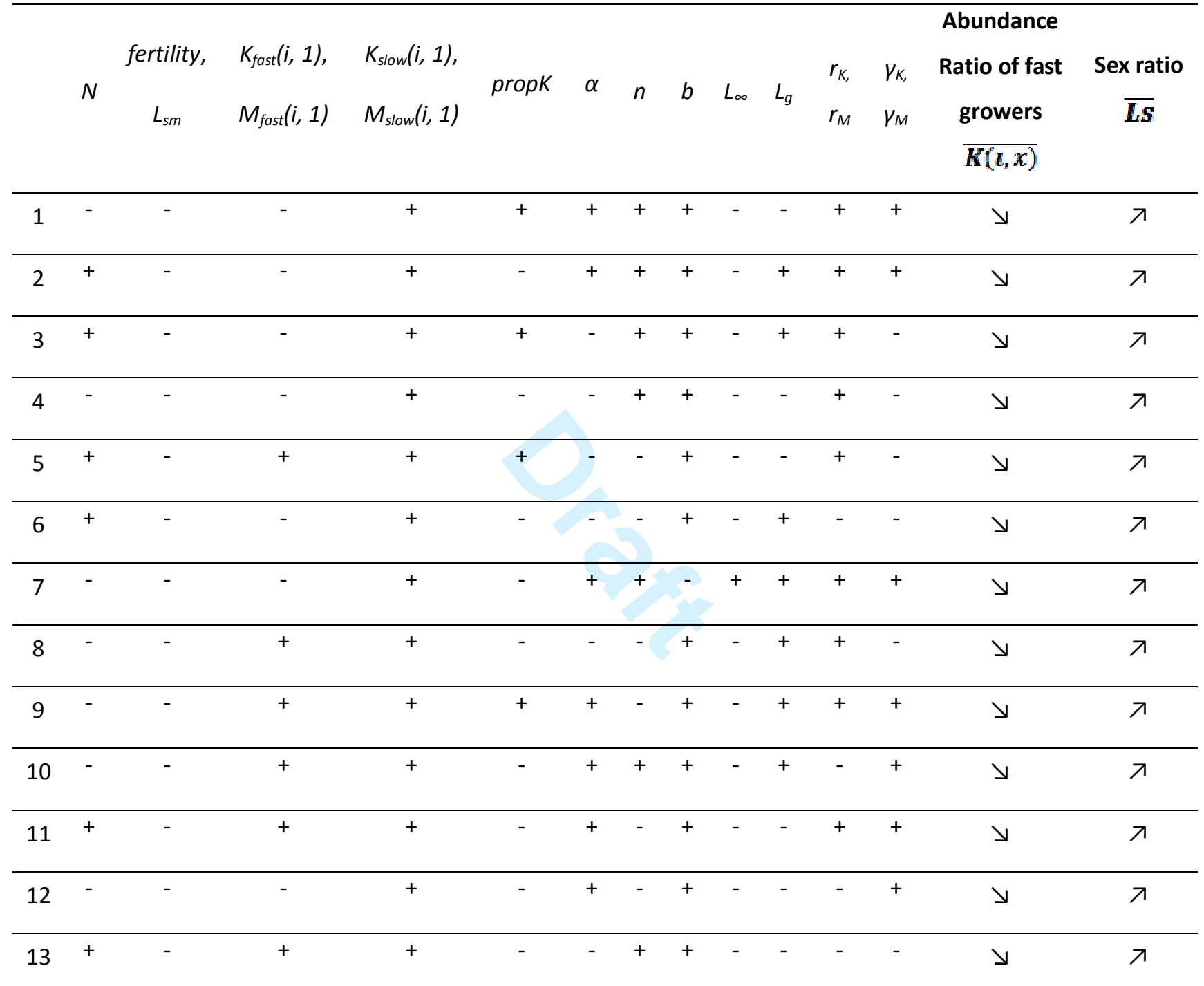




\section{Figures}

844 Fig. 1. Flow chart representing the fish biological pathway.

845 Fig. 2. Algorithm of the model GenEveel.

846 Fig. 3. Output values for the five spatial patterns resulting from the reference simulation.

847 Fig. 4. Simulated mean length at silvering patterns in the 13 combinations of parameters that 848 consistently mimic the pattern described in the literature. These 13 combinations correspond to the 84913 combinations that generate consistent patterns for all the five spatial patterns. Each plot stands 850 for a combination (the number is an identifier of the combination that can be found in table 4) and 851 each line stands for a replicate.

852 Fig. 5. Simulated sex ratio (proportions of females) patterns in the 13 combinations of parameters 853 that consistently mimic the pattern described in the literature. These 13 combinations correspond to 854 the 13 combinations that generate consistent patterns for all the five spatial patterns. Each plot 855 stands for a combination (the number is an identifier of the combination that can be found in table 856 4) and each line stands for a replicate. 


\section{Supplemental Information}

858 Table S1. Results of the 256 combinations. The signs $+/-$ refer to the modalities of the parameters

859 groups. The last five columns represent the spatial patterns. An ascendant arrows stands for positive

860 Mann-Kendall tau value (increasing trend from downstream to upstream). Conversely, a descendant 861 arrow stands for a negative Mann-Kendall tau value. 


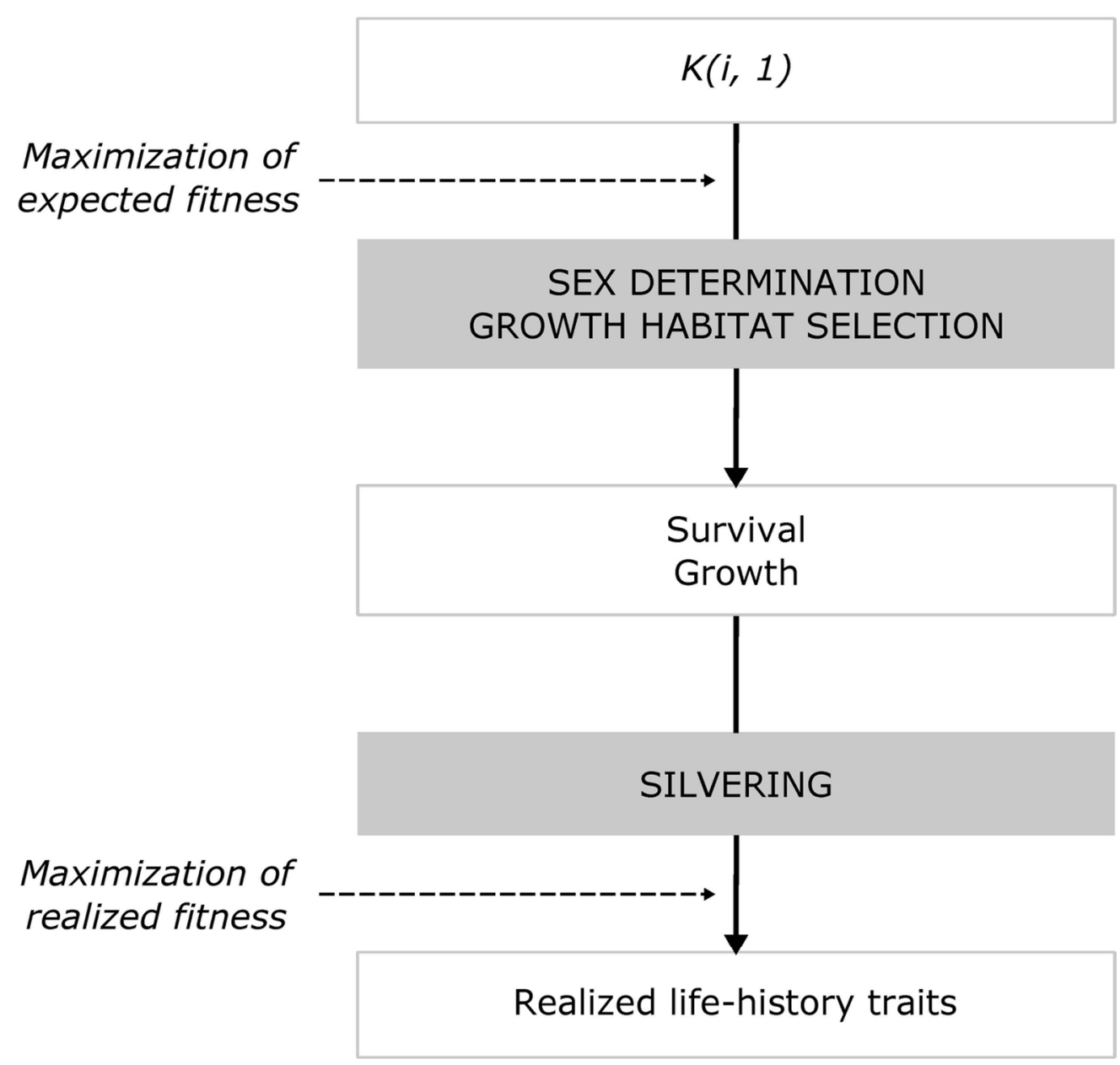

Fig. 1. Flow chart representing the fish biological pathway. $117 \times 112 \mathrm{~mm}(300 \times 300 \mathrm{DPI})$ 


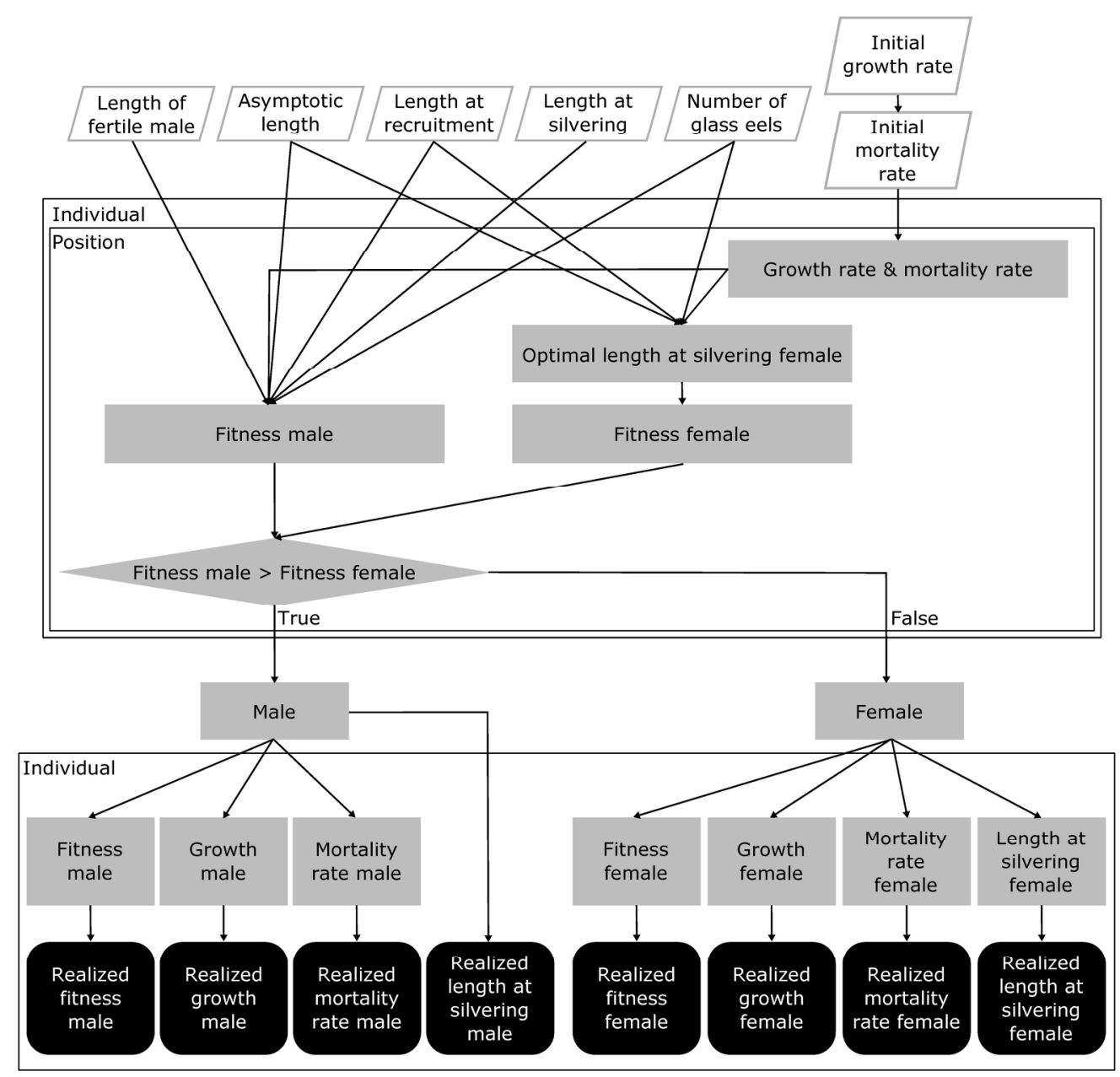

Fig. 2. Algorithm of the model GenEveel.

$198 \times 191 \mathrm{~mm}(300 \times 300$ DPI $)$ 

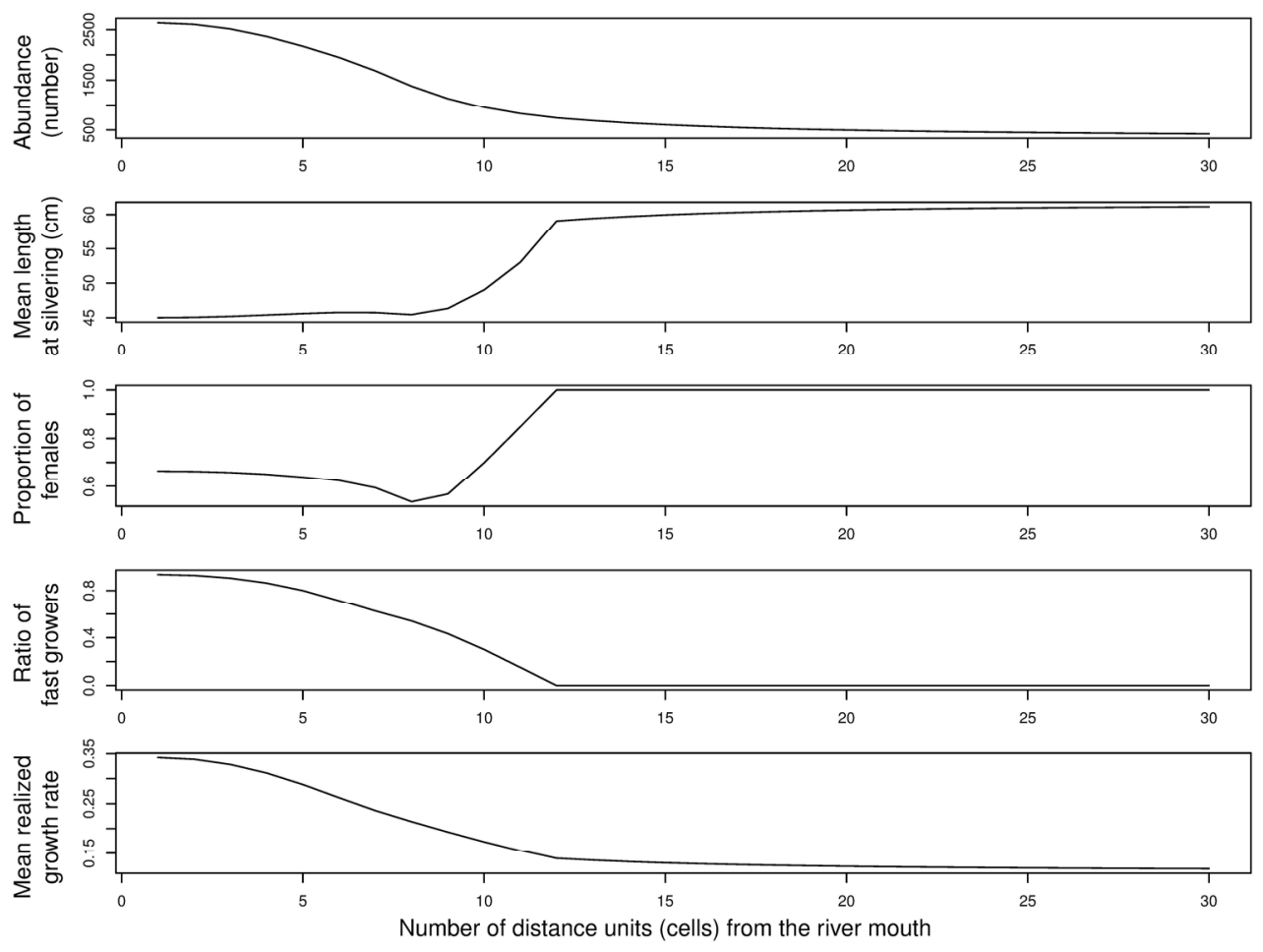

Fig. 3. Output values for the five spatial patterns resulting from the reference simulation.

$182 \times 141 \mathrm{~mm}(300 \times 300 \mathrm{DPI})$ 

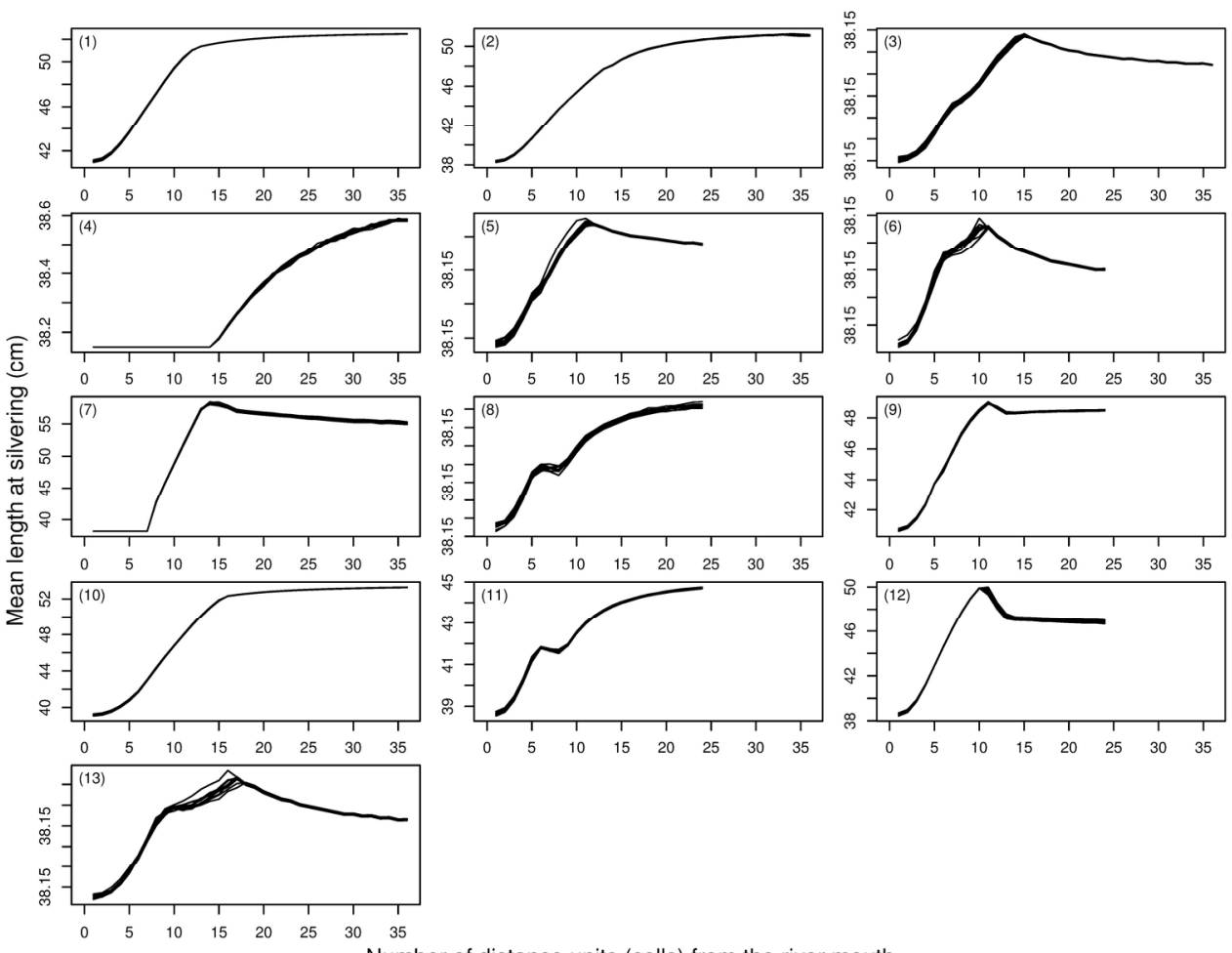

Number of distance units (cells) from the river mouth

Fig. 4. Simulated mean length at silvering patterns in the 13 combinations of parameters that consistently mimic the pattern described in the literature. These 13 combinations correspond to the 13 combinations that generate consistent patterns for all the five spatial patterns. Each plot stands for a combination (the number is an identifier of the combination that can be found in table 4) and each line stands for a replicate.

$182 \times 141 \mathrm{~mm}(300 \times 300 \mathrm{DPI})$ 

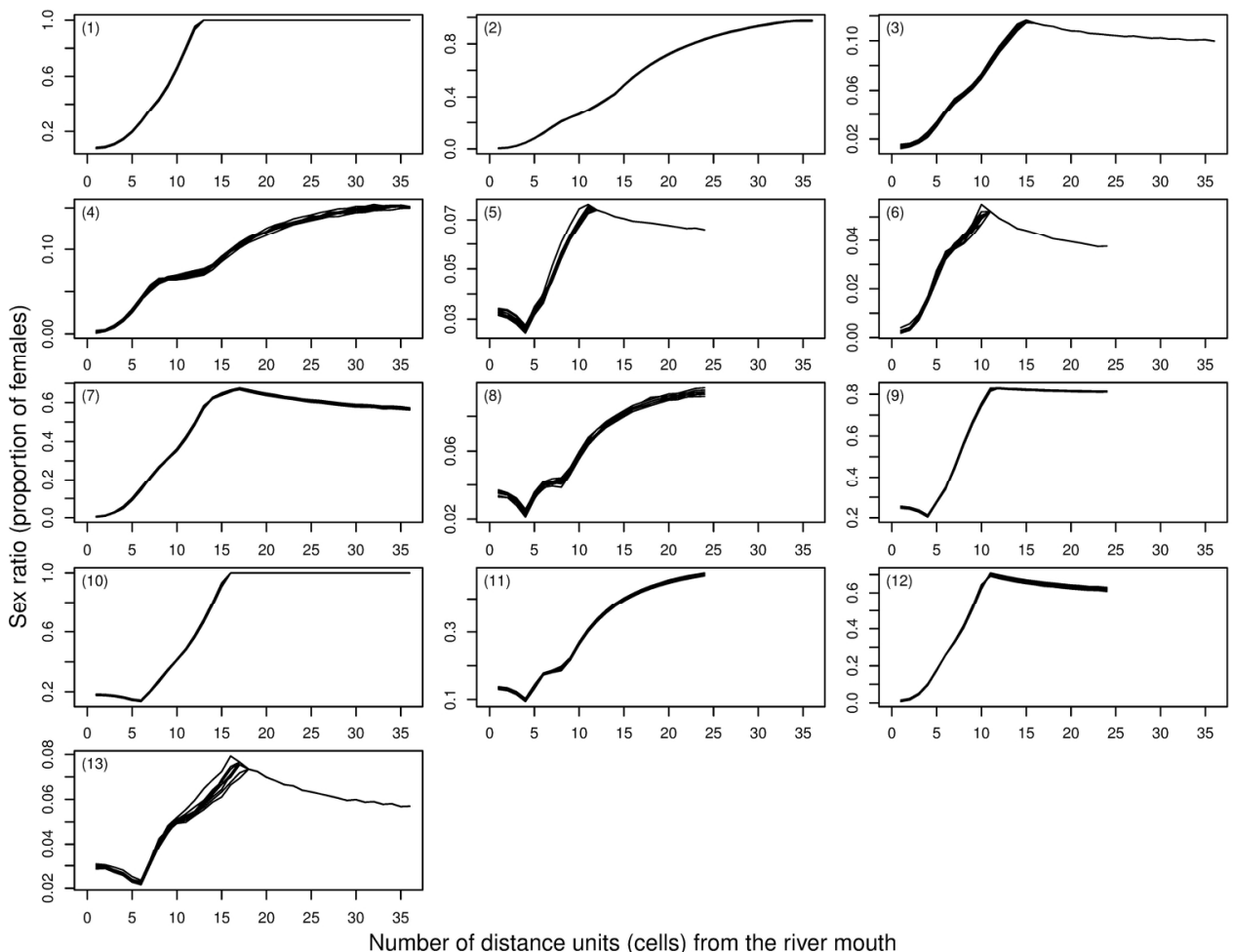

Fig. 5. Simulated sex ratio (proportions of females) patterns in the 13 combinations of parameters that consistently mimic the pattern described in the literature. These 13 combinations correspond to the 13 combinations that generate consistent patterns for all the five spatial patterns. Each plot stands for a combination (the number is an identifier of the combination that can be found in table 4) and each line stands for a replicate.

$182 \times 141 \mathrm{~mm}(300 \times 300 \mathrm{DPI})$ 


\section{Supplemental Information}

2 Table S1. Results of the 256 combinations. The signs +/- refer to the modalities of the parameters groups . The last five columns represent the spatial 3 patterns. An ascendant arrows stands for positive Mann-Kendall tau value (increasing trend from downstream to upstream). Conversely, a descendant arrow 4 stands for a negative Mann-Kendall tau value.

\begin{tabular}{|c|c|c|c|c|c|c|c|c|c|c|c|c|c|c|c|c|c|}
\hline & $N$ & $\begin{array}{c}\text { fertility, } \\
L_{s m}\end{array}$ & $\begin{array}{l}K_{\text {fast }}(i, 1), \\
M_{\text {fast }}(i, 1)\end{array}$ & $\begin{array}{l}K_{\text {slow }}(i, 1), \\
M_{\text {slow }}(i, 1)\end{array}$ & propK & $\alpha$ & $n$ & $b$ & $L_{\infty}$ & $L_{g}$ & $\begin{array}{l}r_{K} \\
r_{M}\end{array}$ & $\begin{array}{l}\gamma_{K} \\
\gamma_{M}\end{array}$ & Abundance & $\begin{array}{l}\text { Mean length } \\
\text { at silvering }\end{array}$ & Sex ratio & $\begin{array}{c}\text { Ratio of fast } \\
\text { growers }\end{array}$ & $\begin{array}{c}\text { Mean realized } \\
\text { growth rate }\end{array}$ \\
\hline 1 & - & - & - & + & + & + & + & + & - & - & + & + & $y$ & $\pi$ & $\pi$ & $y$ & $y$ \\
\hline 2 & + & - & - & + & - & + & + & + & - & + & + & + & $y$ & $\pi$ & ス & $y$ & $y$ \\
\hline 3 & + & - & - & + & + & - & + & + & - & + & + & - & $y$ & $\pi$ & $\pi$ & $y$ & $y$ \\
\hline 4 & - & - & - & + & - & - & + & + & - & - & + & - & $y$ & $\pi$ & $\pi$ & $y$ & $y$ \\
\hline 5 & + & - & + & + & + & - & - & + & - & - & + & - & $y$ & $\pi$ & $\pi$ & $y$ & $y$ \\
\hline 6 & + & - & - & + & - & - & - & + & - & + & - & - & $y$ & $\pi$ & $\pi$ & $y$ & $y$ \\
\hline 7 & - & - & - & + & - & + & + & - & + & + & + & + & $y$ & $\pi$ & $\pi$ & $y$ & $y$ \\
\hline 8 & - & - & + & + & - & - & - & + & - & + & + & - & $y$ & $\pi$ & $\pi$ & $y$ & $y$ \\
\hline 9 & - & - & + & + & + & + & - & + & - & + & + & + & 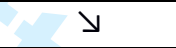 & $\pi$ & 入 & $y$ & $\searrow$ \\
\hline 10 & - & - & + & + & - & + & + & + & - & + & - & + & $y$ & $\pi$ & 入 & $y$ & $\searrow$ \\
\hline 11 & + & - & + & + & - & + & - & + & - & - & + & + & $y$ & $\lambda$ & 入 & $y$ & $y$ \\
\hline 12 & - & - & - & + & - & + & - & + & - & - & - & + & $y$ & 入 & $\pi$ & $y$ & $y$ \\
\hline 13 & + & - & + & + & - & - & + & + & - & - & - & - & $y$ & 入 & $\pi$ & $y$ & $y$ \\
\hline 14 & - & - & - & + & - & - & - & - & + & + & - & - & $y$ & $\lambda$ & $y$ & $y$ & $y$ \\
\hline 15 & + & + & + & - & - & - & + & + & - & - & + & - & $y$ & $\lambda$ & $y$ & $y$ & $y$ \\
\hline 16 & + & - & - & - & - & + & + & - & + & + & - & - & $y$ & $\lambda$ & $y$ & $y$ & $y$ \\
\hline 17 & - & - & - & - & + & - & + & + & - & + & - & + & $y$ & $\pi$ & $y$ & $y$ & $y$ \\
\hline 18 & + & + & + & + & + & - & - & + & + & + & - & - & $y$ & $\pi$ & $y$ & $y$ & $y$ \\
\hline 19 & + & - & - & - & - & - & - & - & + & + & + & + & $y$ & $\lambda$ & $\searrow$ & $y$ & $\searrow$ \\
\hline 20 & - & + & + & + & + & - & + & + & + & - & + & - & $y$ & 入 & $\searrow$ & $y$ & $\searrow$ \\
\hline 21 & + & - & - & - & - & - & + & + & - & - & - & + & $y$ & $\lambda$ & $y$ & $y$ & $y$ \\
\hline 22 & + & - & - & + & - & - & + & - & + & - & + & - & $y$ & $\lambda$ & $y$ & $y$ & $y$ \\
\hline 23 & - & - & - & - & - & - & + & - & + & - & - & + & $y$ & $\lambda$ & $y$ & $y$ & $y$ \\
\hline
\end{tabular}




\begin{tabular}{|c|c|c|c|c|c|c|c|c|c|c|c|c|c|c|c|c|c|}
\hline & $N$ & $\begin{array}{c}\text { fertility, } \\
L_{s m}\end{array}$ & $\begin{array}{l}K_{\text {fast }}(i, 1), \\
M_{\text {fast }}(i, 1)\end{array}$ & $\begin{array}{l}K_{\text {slow }}(i, 1), \\
M_{\text {slow }}(i, 1)\end{array}$ & propK & $\alpha$ & $n$ & $b$ & $L_{\infty}$ & $L_{g}$ & $\begin{array}{l}r_{K} \\
r_{M}\end{array}$ & $\begin{array}{l}\gamma_{K} \\
\gamma_{M}\end{array}$ & Abundance & $\begin{array}{l}\text { Mean length } \\
\text { at silvering }\end{array}$ & Sex ratio & $\begin{array}{c}\text { Ratio of fast } \\
\text { growers }\end{array}$ & $\begin{array}{c}\text { Mean realized } \\
\text { growth rate }\end{array}$ \\
\hline 24 & + & - & + & - & + & - & + & + & - & + & + & + & $y$ & $\pi$ & $y$ & $y$ & $y$ \\
\hline 25 & + & + & - & + & - & - & - & + & + & - & + & - & $y$ & $\pi$ & $y$ & $y$ & $y$ \\
\hline 26 & + & - & + & - & - & - & + & + & + & + & - & - & $y$ & $\pi$ & $y$ & $y$ & $y$ \\
\hline 27 & - & - & + & - & - & - & + & + & - & - & + & + & $y$ & $\pi$ & $y$ & $y$ & $y$ \\
\hline 28 & - & - & - & + & + & - & + & - & + & + & + & - & $y$ & $\pi$ & $y$ & $y$ & $y$ \\
\hline 29 & + & + & + & - & + & - & - & + & - & - & - & - & $y$ & $\pi$ & $y$ & $y$ & $y$ \\
\hline 30 & - & - & + & - & - & - & - & + & + & - & + & - & $y$ & $\lambda$ & $y$ & $y$ & $y$ \\
\hline 31 & + & - & + & - & - & + & - & - & + & - & - & - & $y$ & $\lambda$ & $y$ & $y$ & $y$ \\
\hline 32 & - & + & - & - & + & - & + & + & + & - & + & + & $y$ & $\lambda$ & $\searrow$ & $\searrow$ & $y$ \\
\hline 33 & + & + & + & + & + & - & - & - & + & - & + & + & $\searrow$ & $\lambda$ & $y$ & $\searrow$ & $y$ \\
\hline 34 & + & - & + & + & + & + & - & - & + & + & + & + & $y$ & $\lambda$ & $y$ & $y$ & $y$ \\
\hline 35 & + & + & - & + & + & - & + & + & + & - & - & - & $y$ & $\lambda$ & $y$ & $y$ & $y$ \\
\hline 36 & - & + & + & - & + & - & - & + & + & + & + & + & $\searrow$ & 入 & $\searrow$ & $\searrow$ & $\searrow$ \\
\hline 37 & - & - & - & + & + & - & + & + & + & - & - & + & $y$ & $\lambda$ & $y$ & $y$ & $y$ \\
\hline 38 & - & + & + & - & - & - & + & + & + & + & - & + & $y$ & $\lambda$ & $y$ & $y$ & $\searrow$ \\
\hline 39 & - & + & - & + & - & - & + & + & + & + & - & - & $y$ & $\lambda$ & $y$ & $y$ & $y$ \\
\hline 40 & - & + & - & - & - & - & - & + & + & - & - & + & $\searrow$ & $\lambda$ & $\searrow$ & $\searrow$ & $\searrow$ \\
\hline 41 & + & + & + & - & + & - & + & - & + & + & + & - & $y$ & $\lambda$ & $y$ & $y$ & $\searrow$ \\
\hline 42 & - & + & - & + & + & - & - & + & + & + & + & - & $y$ & $\lambda$ & $y$ & $y$ & $y$ \\
\hline 43 & + & - & + & + & - & - & - & + & + & - & - & + & $y$ & 入 & $\searrow$ & $\searrow$ & $y$ \\
\hline 44 & - & - & + & - & - & + & + & - & + & + & + & - & $y$ & $\lambda$ & $y$ & $y$ & $y$ \\
\hline 45 & + & - & + & + & - & - & - & - & + & + & + & - & $\searrow$ & $\lambda$ & $y$ & $\searrow$ & $y$ \\
\hline 46 & + & - & + & + & + & - & + & + & + & - & + & + & $y$ & $\lambda$ & $y$ & $y$ & $y$ \\
\hline 47 & - & - & - & + & - & - & - & + & + & - & + & + & $y$ & $\pi$ & $y$ & $y$ & $y$ \\
\hline 48 & - & - & + & + & + & - & + & + & - & + & - & - & $y$ & $\lambda$ & $y$ & $y$ & $y$ \\
\hline 49 & + & - & - & + & + & - & - & + & + & + & + & + & $\searrow$ & $\lambda$ & $\searrow$ & $\searrow$ & $\searrow$ \\
\hline 50 & + & + & - & - & - & + & - & + & + & + & - & - & $y$ & $\lambda$ & $y$ & $y$ & $y$ \\
\hline 51 & + & - & - & - & - & - & + & + & - & - & - & + & $y$ & $\lambda$ & $y$ & $y$ & $y$ \\
\hline 52 & - & - & + & + & + & - & - & + & + & + & - & + & $\searrow$ & 入 & $\searrow$ & $\searrow$ & $\searrow$ \\
\hline
\end{tabular}




\begin{tabular}{|c|c|c|c|c|c|c|c|c|c|c|c|c|c|c|c|c|c|}
\hline & $N$ & $\begin{array}{c}\text { fertility, } \\
L_{s m}\end{array}$ & $\begin{array}{l}K_{\text {fast }}(i, 1), \\
M_{\text {fast }}(i, 1)\end{array}$ & $\begin{array}{l}K_{\text {slow }}(i, 1), \\
M_{\text {slow }}(i, 1)\end{array}$ & propK & $\alpha$ & $n$ & $b$ & $L_{\infty}$ & $L_{g}$ & $\begin{array}{l}r_{K} \\
r_{M}\end{array}$ & $\begin{array}{l}\gamma_{K} \\
\gamma_{M}\end{array}$ & Abundance & $\begin{array}{l}\text { Mean length } \\
\text { at silvering }\end{array}$ & Sex ratio & $\begin{array}{c}\text { Ratio of fast } \\
\text { growers }\end{array}$ & $\begin{array}{c}\text { Mean realized } \\
\text { growth rate }\end{array}$ \\
\hline 53 & - & - & - & - & + & - & - & - & + & - & + & + & $y$ & $\lambda$ & $y$ & $y$ & $y$ \\
\hline 54 & - & + & - & - & + & - & + & - & + & + & - & - & $y$ & $\pi$ & $y$ & $y$ & $y$ \\
\hline 55 & - & - & - & - & + & - & - & + & + & + & - & - & $y$ & $\pi$ & $y$ & $y$ & $y$ \\
\hline 56 & - & + & + & - & - & - & - & + & - & + & - & - & $y$ & $\pi$ & $y$ & $y$ & $y$ \\
\hline 57 & - & + & + & - & - & - & + & - & + & - & + & - & $y$ & $\pi$ & $y$ & $y$ & $y$ \\
\hline 58 & - & - & - & - & - & + & - & - & + & - & + & - & $y$ & $\pi$ & $y$ & $y$ & $y$ \\
\hline 59 & + & + & + & - & - & - & - & - & + & + & - & - & $y$ & $\lambda$ & $y$ & $y$ & $y$ \\
\hline 60 & - & + & - & - & - & - & + & + & - & - & - & - & $y$ & $\lambda$ & $y$ & $y$ & $y$ \\
\hline 61 & - & + & + & - & + & - & - & - & + & - & - & - & $y$ & $\pi$ & $y$ & $y$ & $y$ \\
\hline 62 & + & - & + & - & + & - & - & - & + & - & - & + & $y$ & $\lambda$ & $y$ & $y$ & $y$ \\
\hline 63 & + & - & + & - & - & - & + & - & + & - & + & + & $y$ & $\pi$ & $y$ & $y$ & $y$ \\
\hline 64 & + & - & - & - & + & - & + & - & + & + & - & + & $y$ & $\lambda$ & $y$ & $y$ & $y$ \\
\hline 65 & - & - & - & - & + & + & + & - & + & - & - & - & $y$ & $\pi$ & $y$ & $y$ & $y$ \\
\hline 66 & + & - & - & + & - & - & + & + & + & + & - & + & $y$ & $\lambda$ & $y$ & $y$ & $y$ \\
\hline 67 & - & - & + & - & + & - & - & + & - & - & - & + & $y$ & $\pi$ & $y$ & $y$ & $y$ \\
\hline 68 & - & - & - & + & + & - & - & + & - & - & - & - & y & $\lambda$ & $y$ & $y$ & $y$ \\
\hline 69 & - & - & + & - & + & - & + & + & + & - & - & - & $y$ & $\lambda$ & $y$ & $y$ & $y$ \\
\hline 70 & - & - & + & - & + & - & + & - & + & + & + & + & $y$ & $\pi$ & $y$ & $y$ & $y$ \\
\hline 71 & + & - & - & - & + & - & + & + & + & - & + & - & $y$ & $\lambda$ & $y$ & $y$ & $y$ \\
\hline 72 & - & - & + & - & - & - & - & - & + & + & - & + & $y$ & $\pi$ & $y$ & $y$ & $y$ \\
\hline 73 & - & - & - & - & - & - & + & + & + & + & + & - & $y$ & $\lambda$ & $y$ & $y$ & $y$ \\
\hline 74 & + & + & - & - & + & - & - & - & + & - & + & - & $y$ & $\pi$ & $y$ & $y$ & $y$ \\
\hline 75 & + & - & - & - & + & - & - & + & - & - & + & + & $y$ & $\lambda$ & $y$ & $y$ & $y$ \\
\hline 75 & - & - & + & + & - & - & + & - & + & - & - & - & $y$ & $\lambda$ & $y$ & $y$ & $y$ \\
\hline 76 & - & + & - & - & - & - & - & - & + & + & + & - & $y$ & $\lambda$ & $y$ & $y$ & $y$ \\
\hline 78 & + & - & - & - & + & + & - & - & + & + & + & - & $y$ & $\lambda$ & 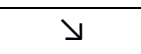 & $y$ & $y$ \\
\hline 79 & + & + & + & - & + & - & + & + & + & - & - & + & $y$ & $\lambda$ & $y$ & $y$ & $y$ \\
\hline 80 & - & - & + & - & + & + & - & - & + & + & - & - & $y$ & $\lambda$ & $y$ & $y$ & $y$ \\
\hline 81 & - & - & + & + & + & - & - & - & + & - & + & - & ע & $\lambda$ & $y$ & y & y \\
\hline
\end{tabular}




\begin{tabular}{|c|c|c|c|c|c|c|c|c|c|c|c|c|c|c|c|c|c|}
\hline & $N$ & $\begin{array}{c}\text { fertility, } \\
L_{s m}\end{array}$ & $\begin{array}{l}K_{\text {fast }}(i, 1), \\
M_{\text {fast }}(i, 1)\end{array}$ & $\begin{array}{l}K_{\text {slow }}(i, 1), \\
M_{\text {slow }}(i, 1)\end{array}$ & propk & $\alpha$ & $n$ & $b$ & $L_{\infty}$ & $L_{g}$ & $\begin{array}{l}r_{K} \\
r_{M}\end{array}$ & $\begin{array}{l}\gamma_{K} \\
\gamma_{M}\end{array}$ & Abundance & $\begin{array}{l}\text { Mean length } \\
\text { at silvering }\end{array}$ & Sex ratio & $\begin{array}{c}\text { Ratio of fast } \\
\text { growers }\end{array}$ & $\begin{array}{c}\text { Mean realized } \\
\text { growth rate }\end{array}$ \\
\hline 82 & - & - & + & + & + & - & - & + & + & + & - & + & $y$ & $\pi$ & $y$ & $y$ & $y$ \\
\hline 83 & + & - & + & + & + & - & + & - & + & + & - & - & $y$ & $\pi$ & $y$ & $y$ & $y$ \\
\hline 84 & + & - & + & - & - & - & - & + & - & + & - & + & $y$ & $\pi$ & $y$ & $y$ & $y$ \\
\hline 85 & + & - & - & + & + & - & - & - & + & - & - & - & $y$ & $\pi$ & $y$ & $y$ & $y$ \\
\hline 86 & - & + & + & + & - & - & - & + & + & - & - & - & $y$ & $\pi$ & $y$ & $y$ & $y$ \\
\hline 87 & + & + & - & - & - & - & + & + & + & + & + & + & $y$ & 入 & $y$ & $y$ & $y$ \\
\hline 88 & + & - & + & - & + & - & - & + & + & + & + & - & $y$ & $\lambda$ & $y$ & $y$ & $y$ \\
\hline 89 & + & + & + & + & - & + & - & - & + & - & + & - & $y$ & $\lambda$ & $y$ & $y$ & $y$ \\
\hline 90 & - & - & - & - & - & - & - & + & - & + & + & + & $y$ & 入 & $y$ & $y$ & $y$ \\
\hline 91 & - & + & + & - & + & - & + & + & - & + & + & - & $y$ & $\lambda$ & $y$ & $y$ & $y$ \\
\hline 92 & + & + & - & - & - & - & + & - & + & - & - & - & $y$ & $\lambda$ & $y$ & $y$ & $y$ \\
\hline 93 & - & - & + & + & - & - & + & + & + & + & + & + & $y$ & $\lambda$ & $y$ & $y$ & $y$ \\
\hline 94 & + & + & - & - & + & - & - & + & + & + & - & + & $y$ & $\pi$ & $y$ & $y$ & $y$ \\
\hline 95 & + & + & - & - & + & - & + & + & - & + & - & - & $\searrow$ & $\lambda$ & $\searrow$ & $y$ & $\searrow$ \\
\hline 96 & + & + & - & - & - & - & - & + & - & + & + & - & $y$ & $\lambda$ & $y$ & $y$ & $y$ \\
\hline 97 & + & - & + & - & + & + & + & - & + & - & + & - & $y$ & 入 & $y$ & $y$ & $y$ \\
\hline 98 & + & + & - & + & + & - & - & + & - & - & - & + & $y$ & 入 & $y$ & $y$ & $y$ \\
\hline 99 & - & + & - & - & + & - & - & + & - & - & + & - & $y$ & $\lambda$ & $y$ & $y$ & $y$ \\
\hline 100 & + & - & - & - & - & - & - & + & + & - & - & - & $y$ & $\lambda$ & $y$ & $y$ & $\searrow$ \\
\hline 101 & + & + & + & + & - & - & + & + & + & + & + & - & $y$ & $\lambda$ & $y$ & $y$ & $y$ \\
\hline 102 & + & - & - & + & + & + & - & + & - & + & - & + & $y$ & $y$ & $y$ & $y$ & $y$ \\
\hline 103 & - & + & - & - & + & + & + & + & - & - & - & + & $\searrow$ & $\searrow$ & $\searrow$ & $\searrow$ & $\searrow$ \\
\hline 104 & + & + & + & - & - & + & + & - & + & + & + & + & $y$ & $\searrow$ & $y$ & $y$ & $y$ \\
\hline 105 & - & + & + & + & + & + & - & - & + & + & + & - & $y$ & $\searrow$ & $y$ & $y$ & $y$ \\
\hline 106 & - & + & - & + & + & - & - & - & + & - & - & + & $y$ & $y$ & $y$ & $y$ & $y$ \\
\hline 107 & - & + & - & - & + & + & - & - & + & + & + & + & $y$ & $\searrow$ & $y$ & $y$ & $y$ \\
\hline 108 & + & + & - & + & - & - & + & + & - & - & + & + & $y$ & $y$ & $y$ & $y$ & $y$ \\
\hline 109 & + & + & + & + & + & - & + & + & - & + & - & + & $y$ & $y$ & $y$ & $y$ & $y$ \\
\hline 110 & + & + & - & + & - & - & - & - & + & + & - & + & $y$ & $y$ & $y$ & $y$ & $y$ \\
\hline
\end{tabular}




\begin{tabular}{|c|c|c|c|c|c|c|c|c|c|c|c|c|c|c|c|c|c|}
\hline & $N$ & $\begin{array}{c}\text { fertility, } \\
L_{s m}\end{array}$ & $\begin{array}{l}K_{\text {fast }}(i, 1), \\
M_{\text {fast }}(i, 1)\end{array}$ & $\begin{array}{l}K_{\text {slow }}(i, 1), \\
M_{\text {slow }}(i, 1)\end{array}$ & propk & $\alpha$ & $n$ & $b$ & $L_{\infty}$ & $L_{g}$ & $\begin{array}{l}r_{K} \\
r_{M}\end{array}$ & $\begin{array}{l}\gamma_{K} \\
\gamma_{M}\end{array}$ & Abundance & $\begin{array}{l}\text { Mean length } \\
\text { at silvering }\end{array}$ & Sex ratio & $\begin{array}{c}\text { Ratio of fast } \\
\text { growers }\end{array}$ & $\begin{array}{c}\text { Mean realized } \\
\text { growth rate }\end{array}$ \\
\hline 111 & - & + & + & + & - & - & - & - & + & + & + & + & $y$ & $y$ & $y$ & $y$ & $y$ \\
\hline 112 & + & + & + & + & + & + & - & + & - & + & + & - & $y$ & $y$ & $y$ & $y$ & $y$ \\
\hline 113 & + & - & - & - & - & + & - & + & - & - & + & - & $y$ & $y$ & $y$ & $y$ & $y$ \\
\hline 114 & + & + & - & + & + & - & + & - & + & + & + & + & $y$ & $y$ & $y$ & $y$ & $y$ \\
\hline 115 & - & + & - & + & + & + & + & - & + & - & + & - & $y$ & $y$ & $y$ & $y$ & $y$ \\
\hline 116 & + & + & - & + & - & + & + & - & + & + & + & - & $y$ & $y$ & $y$ & $y$ & $y$ \\
\hline 117 & - & - & + & - & - & + & - & + & - & - & - & - & $y$ & $y$ & $y$ & $y$ & $y$ \\
\hline 118 & + & - & - & - & + & + & + & + & - & - & - & - & $y$ & $y$ & $y$ & $y$ & $y$ \\
\hline 119 & + & - & - & + & + & + & + & - & + & - & + & + & $y$ & $y$ & $y$ & $y$ & $y$ \\
\hline 120 & - & - & - & - & + & + & - & + & - & + & + & - & $y$ & $y$ & $y$ & $y$ & $y$ \\
\hline 121 & - & + & - & + & - & - & + & - & + & - & + & + & $y$ & $y$ & $y$ & $y$ & $y$ \\
\hline 122 & - & + & + & - & + & + & - & + & - & + & - & + & $y$ & $y$ & $y$ & $y$ & $y$ \\
\hline 123 & + & + & - & - & + & + & + & - & + & - & - & + & $y$ & $y$ & $y$ & $y$ & $y$ \\
\hline 124 & - & + & - & - & - & + & - & + & - & - & + & + & $y$ & $y$ & $y$ & $y$ & $y$ \\
\hline 125 & + & + & + & - & + & + & + & + & - & - & + & + & $y$ & $y$ & $y$ & $y$ & $y$ \\
\hline 126 & - & + & - & + & - & + & - & - & + & - & - & - & $y$ & $y$ & $y$ & $y$ & $y$ \\
\hline 127 & + & + & - & + & - & + & - & + & - & - & - & - & $y$ & $y$ & $y$ & $y$ & $y$ \\
\hline 128 & - & + & + & + & + & - & - & + & - & - & + & + & $y$ & $y$ & $y$ & $y$ & $y$ \\
\hline 129 & + & - & + & - & - & + & + & + & - & + & + & - & $y$ & $y$ & $y$ & $y$ & $y$ \\
\hline 130 & - & + & - & + & + & - & + & + & - & + & + & + & $y$ & $y$ & $y$ & $y$ & $y$ \\
\hline 131 & - & + & + & - & - & + & - & - & + & - & - & + & $y$ & $y$ & $y$ & $y$ & $y$ \\
\hline 132 & - & - & + & + & + & + & + & - & + & - & - & + & $y$ & $y$ & $y$ & $y$ & $y$ \\
\hline 133 & - & - & - & - & - & + & + & + & - & + & - & - & $y$ & $y$ & $y$ & $y$ & $y$ \\
\hline 134 & - & + & + & - & - & + & + & + & - & + & + & + & $y$ & $y$ & $y$ & $y$ & $y$ \\
\hline 135 & + & + & + & - & - & - & - & + & + & - & + & + & $y$ & $y$ & $y$ & $y$ & $y$ \\
\hline 136 & + & + & + & + & - & - & + & - & + & - & - & + & $y$ & $y$ & $y$ & $y$ & $y$ \\
\hline 137 & - & - & + & + & - & + & - & - & + & - & + & + & $y$ & $y$ & $y$ & $y$ & $y$ \\
\hline 138 & + & + & - & + & + & + & - & - & + & + & - & - & $y$ & $y$ & $y$ & $y$ & $y$ \\
\hline 139 & - & + & + & - & + & + & + & - & + & - & + & + & $y$ & $y$ & $y$ & $y$ & $y$ \\
\hline
\end{tabular}




\begin{tabular}{|c|c|c|c|c|c|c|c|c|c|c|c|c|c|c|c|c|c|}
\hline & $N$ & $\begin{array}{c}\text { fertility, } \\
L_{s m}\end{array}$ & $\begin{array}{l}K_{\text {fast }}(i, 1), \\
M_{\text {fast }}(i, 1)\end{array}$ & $\begin{array}{l}K_{\text {slow }}(i, 1), \\
M_{\text {slow }}(i, 1)\end{array}$ & propK & $\alpha$ & $n$ & $b$ & $L_{\infty}$ & $L_{g}$ & $\begin{array}{l}r_{K} \\
r_{M}\end{array}$ & $\begin{array}{l}\gamma_{K} \\
\gamma_{M}\end{array}$ & Abundance & $\begin{array}{l}\text { Mean length } \\
\text { at silvering }\end{array}$ & Sex ratio & $\begin{array}{c}\text { Ratio of fast } \\
\text { growers }\end{array}$ & $\begin{array}{c}\text { Mean realized } \\
\text { growth rate }\end{array}$ \\
\hline 140 & - & + & - & + & - & - & - & + & - & + & - & + & $y$ & $y$ & $y$ & $y$ & $y$ \\
\hline 141 & + & - & - & + & - & + & - & - & + & - & - & + & $y$ & $y$ & $y$ & $y$ & $y$ \\
\hline 142 & + & + & - & - & - & + & - & - & + & - & + & + & $y$ & $y$ & $y$ & $y$ & $y$ \\
\hline 143 & - & + & - & + & + & + & - & + & - & + & - & - & $y$ & $y$ & $y$ & $y$ & $y$ \\
\hline 144 & + & + & - & + & + & - & + & - & + & + & + & + & $y$ & $y$ & $y$ & $y$ & $y$ \\
\hline 145 & + & + & - & - & - & + & + & + & - & + & - & + & $y$ & $y$ & $y$ & $y$ & $y$ \\
\hline 146 & - & + & + & + & - & + & - & + & - & - & + & - & $y$ & $y$ & $y$ & $y$ & $y$ \\
\hline 147 & + & + & + & - & + & + & - & - & + & + & - & + & $y$ & $y$ & $y$ & $y$ & $y$ \\
\hline 148 & - & + & - & - & - & + & + & - & + & + & - & + & $y$ & $\searrow$ & $\searrow$ & $\searrow$ & $y$ \\
\hline 149 & + & - & + & + & + & + & + & + & - & - & - & + & $y$ & $y$ & $y$ & $y$ & $y$ \\
\hline 150 & - & - & - & + & + & + & - & - & + & + & - & + & $y$ & $y$ & $y$ & $y$ & $y$ \\
\hline 151 & + & + & + & + & - & - & - & + & - & + & + & + & $y$ & $y$ & $y$ & $y$ & $y$ \\
\hline 152 & + & - & + & - & + & + & - & + & - & + & - & - & $y$ & $y$ & $\searrow$ & $y$ & $\searrow$ \\
\hline 153 & - & + & + & + & - & - & + & + & - & - & - & + & $y$ & $y$ & $y$ & $y$ & $y$ \\
\hline 154 & - & + & + & + & - & + & + & - & + & + & - & - & $y$ & $y$ & $y$ & $y$ & $y$ \\
\hline 155 & + & + & - & + & + & + & + & + & - & - & + & - & $y$ & $y$ & $y$ & $y$ & $y$ \\
\hline 156 & + & + & + & - & - & + & - & + & - & - & - & + & $y$ & $y$ & $y$ & $y$ & $y$ \\
\hline 157 & - & + & + & + & + & - & + & - & + & + & - & + & $y$ & $y$ & $y$ & $y$ & $\searrow$ \\
\hline 158 & + & + & + & + & + & + & + & - & + & - & - & - & $y$ & $y$ & $y$ & $y$ & $y$ \\
\hline 159 & + & + & + & + & - & + & + & + & - & + & - & - & $y$ & $y$ & $y$ & $y$ & $y$ \\
\hline 160 & + & + & - & - & + & + & - & + & - & + & + & + & $y$ & $y$ & $y$ & $y$ & $y$ \\
\hline 161 & - & + & - & + & - & + & + & + & - & + & + & - & $\searrow$ & $\lambda$ & $y$ & $y$ & $y$ \\
\hline 162 & - & - & - & + & + & + & - & + & + & - & + & - & $y$ & $\lambda$ & - & $y$ & $y$ \\
\hline 163 & - & - & + & - & - & + & + & + & + & - & - & + & $y$ & $\pi$ & - & $y$ & $y$ \\
\hline 164 & - & + & - & + & + & + & + & + & + & + & - & + & $y$ & $\lambda$ & - & $y$ & $y$ \\
\hline 165 & - & + & + & - & + & + & + & + & + & + & - & - & $\searrow$ & $\lambda$ & - & $\searrow$ & $\searrow$ \\
\hline 166 & - & + & + & + & - & + & + & + & + & - & + & + & $y$ & $\lambda$ & - & $y$ & $y$ \\
\hline 167 & - & - & - & - & + & + & + & + & + & + & + & + & $y$ & $\pi$ & - & $y$ & $y$ \\
\hline 168 & + & + & + & - & + & + & - & + & + & - & + & - & $y$ & 入 & - & $y$ & $y$ \\
\hline
\end{tabular}




\begin{tabular}{|c|c|c|c|c|c|c|c|c|c|c|c|c|c|c|c|c|c|}
\hline & $N$ & $\begin{array}{c}\text { fertility, } \\
L_{s m}\end{array}$ & $\begin{array}{l}K_{\text {fast }}(i, 1), \\
M_{\text {fast }}(i, 1)\end{array}$ & $\begin{array}{l}K_{\text {slow }}(i, 1), \\
M_{\text {slow }}(i, 1)\end{array}$ & propK & $\alpha$ & $n$ & $b$ & $L_{\infty}$ & $L_{g}$ & $\begin{array}{l}r_{K} \\
r_{M}\end{array}$ & $\begin{array}{l}\gamma_{K} \\
\gamma_{M}\end{array}$ & Abundance & $\begin{array}{l}\text { Mean length } \\
\text { at silvering }\end{array}$ & Sex ratio & $\begin{array}{c}\text { Ratio of fast } \\
\text { growers }\end{array}$ & $\begin{array}{c}\text { Mean realized } \\
\text { growth rate }\end{array}$ \\
\hline 169 & + & - & + & + & + & + & - & + & + & - & - & - & $y$ & $\lambda$ & - & $y$ & $y$ \\
\hline 170 & - & + & - & - & + & + & - & + & + & - & - & - & $y$ & 入 & - & $y$ & $y$ \\
\hline 171 & - & + & + & + & + & + & - & + & + & - & - & + & $y$ & $\pi$ & - & $y$ & $y$ \\
\hline 172 & - & - & + & + & - & + & - & + & + & + & - & - & $y$ & 入 & - & $y$ & $y$ \\
\hline 173 & + & + & - & - & + & + & + & + & + & + & + & - & $y$ & $\pi$ & - & $y$ & $y$ \\
\hline 174 & + & - & - & + & - & + & - & + & + & + & + & - & $y$ & 入 & - & $y$ & $y$ \\
\hline 175 & + & + & + & - & - & + & + & + & + & - & - & - & $y$ & $\pi$ & - & $y$ & $y$ \\
\hline 176 & - & - & - & + & - & + & + & + & + & - & - & - & $y$ & $\lambda$ & - & $y$ & $y$ \\
\hline 177 & + & - & - & - & - & + & + & + & + & - & + & + & $y$ & 入 & - & $y$ & $y$ \\
\hline 178 & - & + & - & + & - & + & - & + & + & + & + & + & $y$ & 入 & - & $y$ & $y$ \\
\hline 179 & - & - & + & - & + & + & - & + & + & - & + & + & $y$ & 入 & - & $y$ & $y$ \\
\hline 180 & + & + & + & + & + & + & + & + & + & + & + & + & $y$ & $\pi$ & - & $y$ & $y$ \\
\hline 181 & + & + & - & + & - & + & + & + & + & - & - & + & $y$ & $\lambda$ & - & $y$ & $\searrow$ \\
\hline 182 & + & + & - & + & + & + & - & + & + & - & + & + & $y$ & $\lambda$ & - & $y$ & $y$ \\
\hline 183 & + & - & - & + & + & + & + & + & + & + & - & - & $y$ & $\lambda$ & - & $y$ & $y$ \\
\hline 184 & + & - & + & - & - & + & - & + & + & + & + & + & $y$ & $\lambda$ & - & $y$ & $y$ \\
\hline 185 & - & - & - & - & - & + & - & + & + & + & - & + & $y$ & 入 & - & $y$ & $y$ \\
\hline 186 & + & - & - & - & + & + & - & + & + & - & - & + & $y$ & $\lambda$ & - & $y$ & $y$ \\
\hline 187 & - & - & + & + & + & + & + & + & + & + & + & - & $y$ & 入 & - & $y$ & $y$ \\
\hline 188 & + & - & + & + & - & + & + & + & + & - & + & - & $y$ & $\pi$ & - & $y$ & $y$ \\
\hline 189 & + & - & + & - & + & + & + & + & + & + & - & + & $y$ & $\lambda$ & - & $y$ & $y$ \\
\hline 190 & - & + & - & - & - & + & + & + & + & - & + & - & $y$ & $\pi$ & - & $y$ & $y$ \\
\hline 191 & - & + & + & - & - & + & - & + & + & + & + & - & $y$ & & - & $y$ & $\searrow$ \\
\hline 192 & + & + & - & - & - & + & + & - & - & - & + & - & $y$ & - & - & $y$ & $y$ \\
\hline 193 & - & - & + & + & - & + & + & - & - & - & + & - & $y$ & - & - & $y$ & $y$ \\
\hline 194 & + & + & - & + & + & - & - & - & - & + & + & - & $y$ & - & - & $y$ & $y$ \\
\hline 195 & + & + & + & - & + & - & - & - & - & + & + & + & $y$ & - & - & $y$ & $y$ \\
\hline 196 & - & - & - & + & + & + & + & - & - & + & - & - & $y$ & - & - & $y$ & $y$ \\
\hline 197 & - & + & + & + & + & - & - & - & - & + & - & - & $y$ & - & - & $y$ & $y$ \\
\hline
\end{tabular}




\begin{tabular}{|c|c|c|c|c|c|c|c|c|c|c|c|c|c|c|c|c|c|}
\hline & $N$ & $\begin{array}{c}\text { fertility, } \\
L_{s m}\end{array}$ & $\begin{array}{l}K_{\text {fast }}(i, 1), \\
M_{\text {fast }}(i, 1)\end{array}$ & $\begin{array}{l}K_{\text {slow }}(i, 1), \\
M_{\text {slow }}(i, 1)\end{array}$ & propK & $\alpha$ & $n$ & $b$ & $L_{\infty}$ & $L_{g}$ & $\begin{array}{l}r_{K} \\
r_{M}\end{array}$ & $\begin{array}{l}\gamma_{K} \\
\gamma_{M}\end{array}$ & Abundance & $\begin{array}{l}\text { Mean length } \\
\text { at silvering }\end{array}$ & Sex ratio & $\begin{array}{c}\text { Ratio of fast } \\
\text { growers }\end{array}$ & $\begin{array}{c}\text { Mean realized } \\
\text { growth rate }\end{array}$ \\
\hline 198 & - & - & - & + & + & - & - & - & - & + & + & + & $y$ & - & - & $y$ & $y$ \\
\hline 199 & + & - & + & - & + & - & + & - & - & - & - & - & $y$ & - & - & $y$ & $y$ \\
\hline 200 & - & + & + & - & - & + & + & - & - & - & - & - & $y$ & - & - & $y$ & $y$ \\
\hline 201 & + & + & + & - & - & - & + & - & - & + & - & + & $y$ & - & - & $y$ & $y$ \\
\hline 202 & - & - & + & + & + & + & - & - & - & - & - & - & $y$ & - & - & $y$ & $y$ \\
\hline 203 & - & + & - & - & - & - & + & - & - & + & + & + & $y$ & - & - & $y$ & $y$ \\
\hline 204 & + & + & - & + & - & + & - & - & - & + & + & + & $y$ & - & - & $y$ & $y$ \\
\hline 205 & - & + & + & + & - & - & + & - & - & + & + & - & $y$ & - & - & $y$ & $y$ \\
\hline 206 & - & - & - & - & + & + & - & - & - & - & - & + & $y$ & - & - & $y$ & $y$ \\
\hline 207 & + & - & + & + & - & - & + & - & - & + & + & + & $y$ & - & - & $y$ & $y$ \\
\hline 208 & - & - & + & - & + & + & + & - & - & + & - & + & $y$ & - & - & $y$ & $y$ \\
\hline 209 & - & + & + & + & + & + & + & - & - & + & + & + & $y$ & - & - & $y$ & $y$ \\
\hline 210 & - & + & - & + & + & + & - & - & - & - & + & + & $y$ & - & - & $y$ & $\searrow$ \\
\hline 211 & + & - & - & - & + & + & + & - & - & + & + & + & $y$ & - & - & $y$ & $y$ \\
\hline 212 & - & - & - & - & - & + & + & - & - & - & + & + & $y$ & - & - & $y$ & $y$ \\
\hline 213 & - & - & + & - & - & + & - & - & - & + & + & + & $y$ & - & - & $y$ & $y$ \\
\hline 214 & + & + & - & - & - & - & - & - & - & - & - & + & $y$ & - & - & $y$ & $y$ \\
\hline 215 & - & - & - & - & - & - & - & - & - & - & - & - & $y$ & - & - & $y$ & $y$ \\
\hline 216 & + & + & + & + & + & + & - & - & - & - & - & + & $y$ & - & - & $y$ & $y$ \\
\hline 217 & - & + & + & - & + & + & - & - & - & - & + & - & $y$ & - & - & $y$ & $y$ \\
\hline 218 & - & + & + & - & - & - & - & - & - & - & + & + & $y$ & - & - & $y$ & $\searrow$ \\
\hline 219 & - & + & - & - & + & - & - & - & - & + & - & + & $y$ & - & - & $y$ & $y$ \\
\hline 220 & - & + & + & - & + & - & + & - & - & - & - & + & $y$ & - & - & $y$ & $y$ \\
\hline 221 & - & - & + & + & - & - & - & - & - & - & - & + & $y$ & - & - & $y$ & $y$ \\
\hline 223 & + & - & - & + & + & + & - & - & - & - & + & - & $y$ & - & - & $y$ & $y$ \\
\hline 224 & + & + & - & + & + & + & + & - & - & + & - & + & $y$ & - & - & $y$ & $y$ \\
\hline 225 & - & - & + & - & - & - & + & - & - & + & - & - & $y$ & - & - & $y$ & $y$ \\
\hline 227 & + & - & - & - & - & + & - & - & - & + & - & + & $y$ & - & - & $y$ & $y$ \\
\hline 228 & + & + & + & - & - & + & - & - & - & + & + & - & $y$ & - & - & $y$ & $y$ \\
\hline
\end{tabular}




\begin{tabular}{|c|c|c|c|c|c|c|c|c|c|c|c|c|c|c|c|c|c|}
\hline & $N$ & $\begin{array}{c}\text { fertility, } \\
L_{s m}\end{array}$ & $\begin{array}{l}K_{\text {fast }}(i, 1), \\
M_{\text {fast }}(i, 1)\end{array}$ & $\begin{array}{l}K_{\text {slow }}(i, 1), \\
M_{\text {slow }}(i, 1)\end{array}$ & propK & $\alpha$ & $n$ & $b$ & $L_{\infty}$ & $L_{g}$ & $\begin{array}{l}r_{K} \\
r_{M}\end{array}$ & $\begin{array}{l}\gamma_{K} \\
\gamma_{M}\end{array}$ & Abundance & $\begin{array}{l}\text { Mean length } \\
\text { at silvering }\end{array}$ & Sex ratio & $\begin{array}{c}\text { Ratio of fast } \\
\text { growers }\end{array}$ & $\begin{array}{c}\text { Mean realized } \\
\text { growth rate }\end{array}$ \\
\hline 229 & + & + & + & - & + & + & + & - & - & + & - & - & $y$ & - & - & $y$ & $y$ \\
\hline 230 & + & + & - & - & + & - & + & - & - & - & + & + & $y$ & - & - & $y$ & $y$ \\
\hline 231 & - & + & + & + & - & + & - & - & - & + & - & + & $y$ & - & - & $y$ & $y$ \\
\hline 232 & + & - & - & - & + & - & - & - & - & + & - & - & $y$ & - & - & $y$ & $y$ \\
\hline 233 & - & - & - & + & - & + & - & - & - & + & + & - & $y$ & - & - & $y$ & $y$ \\
\hline 234 & + & - & + & - & + & + & - & - & - & - & + & + & $y$ & - & - & $y$ & $y$ \\
\hline 235 & + & + & - & + & - & - & + & - & - & + & - & - & $y$ & - & - & $y$ & $y$ \\
\hline 236 & + & + & - & - & + & + & - & - & - & - & - & - & $y$ & - & - & $y$ & $y$ \\
\hline 237 & - & + & - & + & + & - & + & - & - & - & - & - & $y$ & - & - & $y$ & $y$ \\
\hline 238 & - & - & + & - & + & - & - & - & - & + & + & - & $y$ & - & - & $y$ & $y$ \\
\hline 239 & + & - & - & + & - & - & - & - & - & - & + & + & $\searrow$ & - & - & $y$ & $y$ \\
\hline 240 & - & + & - & - & - & + & - & - & - & + & - & - & $y$ & - & - & $y$ & $y$ \\
\hline 241 & + & + & + & + & + & - & + & - & - & - & + & - & $y$ & - & - & $y$ & $y$ \\
\hline 242 & - & - & - & - & + & - & + & - & - & - & + & - & $y$ & - & - & $y$ & $y$ \\
\hline 243 & + & - & + & + & - & + & - & - & - & + & - & - & $y$ & - & - & $y$ & $y$ \\
\hline 244 & - & + & - & + & - & - & - & - & - & - & + & - & $y$ & - & - & $y$ & $y$ \\
\hline 245 & + & - & + & - & - & + & + & - & - & - & - & + & $y$ & - & - & $y$ & $y$ \\
\hline 246 & + & - & - & - & - & - & + & - & - & + & + & - & $y$ & - & - & $y$ & $y$ \\
\hline 247 & + & - & + & + & + & - & - & - & - & + & - & + & $y$ & - & - & $y$ & $y$ \\
\hline 248 & - & - & + & + & + & - & + & - & - & - & + & + & $y$ & - & - & $y$ & $y$ \\
\hline 249 & + & - & + & + & + & + & + & - & - & + & + & - & $y$ & - & - & $y$ & $y$ \\
\hline 250 & + & + & + & + & - & - & - & - & - & - & - & - & $y$ & - & - & $y$ & $y$ \\
\hline 251 & + & - & - & + & - & + & + & - & - & - & - & - & $y$ & - & - & $y$ & $y$ \\
\hline 252 & - & + & - & - & + & + & + & - & - & + & + & - & $y$ & - & - & $\searrow$ & $y$ \\
\hline 253 & + & - & - & + & + & - & + & - & - & - & - & + & $y$ & - & - & $y$ & $y$ \\
\hline 254 & + & + & + & + & - & + & + & - & - & - & + & + & $y$ & - & - & $y$ & $y$ \\
\hline 255 & + & - & + & - & - & - & - & - & - & - & + & - & $y$ & - & - & $y$ & $y$ \\
\hline 256 & - & + & - & + & - & + & + & - & - & - & - & + & $y$ & - & - & $y$ & $y$ \\
\hline
\end{tabular}

